\title{
Economic Burden of Chronic III Health and Injuries for Households in Low- and Middle-Income Countries
}

\author{
Beverley M. Essue, Tracey-Lea Laba, Felicia Knaul, \\ Annie Chu, Hoang Van Minh, Thi Kim Phuong Nguyen, \\ and Stephen Jan
}

\section{INTRODUCTION}

The World Health Report 2000: Health Systems: Improving Performance (WHO 2000); the World Health Organization (WHO) resolution on sustainable health financing, universal health coverage, and social health insurance (WHO 2005); and the World Health Report: Health Systems Financing: The Path to Universal Coverage (WHO 2010) all highlighted the substantial economic burden faced by individuals with no access to affordable, high-quality health care. These reports placed the need to address the economic effect of illness-in particular, catastrophic and impoverishing health expenditure - on the global health policy agenda.

Financial protection-a core element of universal health coverage-aims to ensure that people receive the health care services they require without facing financial ruin (WHO 2010). Devising strategies to protect populations from financial risk has become a major focus of global health policy development (WHO and World Bank 2014).

Affordable access to high-quality health care is now considered a basic human right and a critical step to the achievement of sustainable economic and social development and the elimination of poverty (Sustainable
Development Solutions Network 2014; WHO 2015). This imperative is reflected in the third Sustainable Development Goal, which sets a target for achieving universal health coverage, including financial risk protection; access to high-quality essential health care services; and access to safe, effective, high-quality, and affordable essential medicines and vaccines for all (UN General Assembly 2015). This commitment is echoed in the World Bank's recent call to eradicate impoverishment owing to health care expenditures by 2030 (Kim 2014).

A lack of both prepayment mechanisms and the means and resources to pool risks has limited the capacity of many health care systems to provide access to high-quality health care services. As a result, for decades, many health systems, particularly in low- and middle-income countries (LMICs), have relied heavily on private payments in the form of out-of-pocket costs to fund health care. In 2014, 18 percent of total health expenditure globally came from out-of-pocket payments (WHO 2014). The burden is even greater in LMICs. In 2014, out-of-pocket payments equaled approximately 39 percent of total health expenditure for low-income countries, 56 percent for lower-middle-income countries, and 30 percent for upper-middle-income countries (WHO 2016). 
Relying on out-of-pocket costs to finance health care is both inefficient and inequitable and places a major financial strain on individuals and households (WHO 2010). Out-of-pocket costs can perpetuate poverty and lead many individuals to delay or forgo necessary care (Peters and others 2008; van Doorslaer and others 2006). This link, where the household's investment in health further impoverishes that household, can lead to a continuous cycle of poor health and poverty (Knaul, Wong, and Arreola-Ornelas 2012).

This burden is of particular concern for persons with chronic diseases, for whom repeated and lifelong costs are associated with the management and treatment of illness (Kankeu and others 2013). For example, in some countries, a household may have to pay as much as eight days' worth of wages to purchase one month's supply of only one of the multiple medicines required for the optimal treatment of cardiovascular disease (CVD) or diabetes (Cameron and others 2009; Gelders and others 2006). In more extreme cases, the costs of treatment for chronic and long-term conditions such as human immunodeficiency virus/acquired immune deficiency syndrome (HIV/AIDS) and surgery for some cancers have kept patients confined to hospitals indefinitely pending payment to the hospitals or forced them to stop treatment altogether (Human Rights Watch 2006). Although households, even those that are already impoverished, may be able to manage a one-time shock and recover in the short run (for example, over a period of a week or a month), they may not be able to withstand the ongoing costs of treatment for chronic diseases.

Furthermore, LMICs are undergoing a protracted epidemiological transition (Frenk and others 1989). Underfunded and weak health systems continue to face a backlog of acute diseases and conditions associated with poverty, together with the onslaught of costly and chronic noncommunicable diseases (NCDs), conditions that affect the entire population at all income levels. This situation inevitably results in competing priorities about which services to include in essential packages of care and which to cover through national insurance funds (Beaglehole and others 2011). However, evidence is lacking on the household-level economic burden associated with certain categories of disease, particularly chronic diseases. Such evidence would inform global health policy development by highlighting where the greatest gains in financial protection might be realized (Shrime and others 2015) and help governments prioritize the measures needed to move toward universal health coverage.

This chapter estimates the burden of catastrophic health expenditure (CHE) associated with chronic ill health and injuries in LMICs and describes the broader economic effects on households. It is organized as follows.
We begin by estimating the population-level burden of CHE - the most common indicator of the household economic burden of health expenditure-and draw on empirical research of specific chronic diseases and injuries to estimate the prevalence of $\mathrm{CHE}$ associated with seven categories of conditions: cancers, CVDs, chronic infectious diseases, endocrine diseases, injuries, renal diseases, and respiratory diseases. We then draw on a review of NCDs in LMICs to describe the broader household economic effects associated with ill health, including impoverishing health expenditure, productivity effects, distressed financing, and treatment discontinuation. We discuss implications of the results for improving financial protection and offer directions for future research.

\section{POPULATION-LEVEL ESTIMATES OF CATASTROPHIC AND IMPOVERISHING HEALTH EXPENDITURES}

Catastrophic and impoverishing health expenditures, also referred to as medical impoverishment, continue to challenge health systems around the world and pose a key barrier to improving economic and social well-being (Knaul, Wong, and Arreola-Ornelas 2012). Very conservative estimates suggest that, globally, at least 150 million people a year face financial catastrophe and 100 million are driven into poverty by expenditure on health care (Xu and others 2007).

CHE and impoverishing health expenditure are interrelated, but distinct, concepts (figure 6.1). Consensus is lacking on the definition of what constitutes a

Figure 6.1 Definition of Catastrophic and Impoverishing Health Expenditures

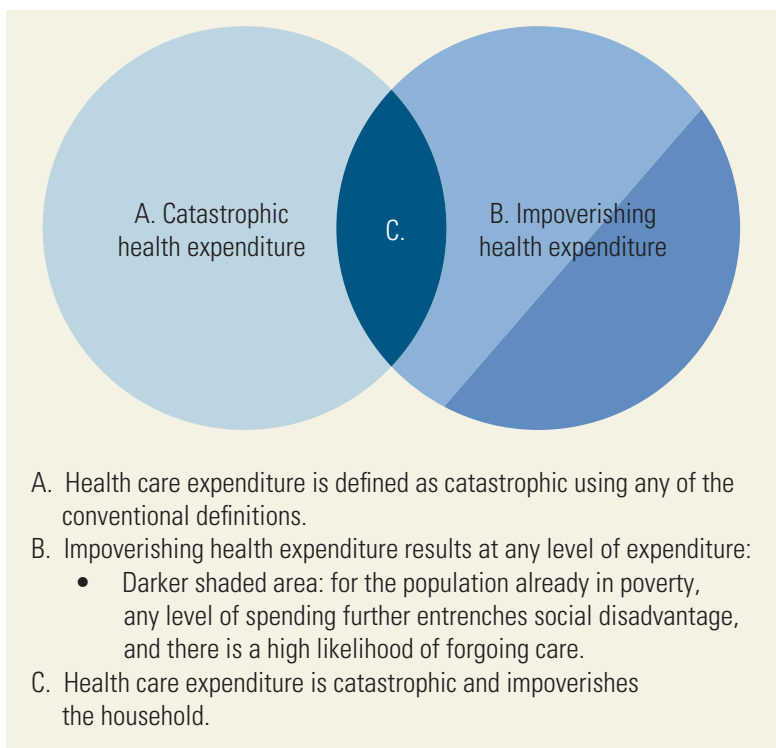


catastrophic level of expenditure for households and the most appropriate denominator for measuring $\mathrm{CHE}$ : expenditure, income, or consumption (Knaul, Wong, and Arreola-Ornelas 2012; O'Donnell and others 2007). Box 6.1 distinguishes between these two concepts.

The economic burden associated with ill health extends beyond paying for care (table 6.1). Household members cope with the onset of illness in various ways, and the response can influence their treatment-seeking behavior (McIntyre and others 2006; Okoli and Cleary 2011; Sauerborn, Adams, and Hien 1996; Xu and others 2007). When faced with ill health, particularly unexpected events, the household must mobilize resources to pay for health care, often by borrowing money, using limited savings, and selling assets_-all of which can negatively affect the long-term economic well-being of the household, including its ability to deal with ongoing health care needs and future health shocks (Kruk, Goldmann, and Galea 2009; McIntyre and others 2006; Peters and others 2008; Russell 2004). Ill health can also affect the productivity of both the sick individual and a family caregiver, leading to loss of paid employment or educational opportunities. All these factors severely impair the family's capacity to earn income in both temporary and longer-term ways.

Financial protection through tax-financed social health insurance programs is a major pillar of efforts by national governments to achieve universal health coverage. Indeed, there is evidence of the extent to which health insurance-based measures effectively provide financial protection by curbing the burden of medical expenditure (Essue and others 2015; Knaul, Arreola-Ornelas, and Méndez-Carniado 2016). Although progress has been made at a population level, research shows variations in the financial protection afforded to different subgroups (box 6.2).

\section{Box 6.1}

\section{Conceptual Relationship between Catastrophic} Health Expenditure and Impoverishing Health Expenditure

Conceptually, catastrophic health expenditure is a measure of the burden of health care expenditure (that is, out-ofpocket costs) on a household's available resources. It can result from sizable and unpredictable one-off payments and from a steady flow of unbudgeted medical bills, including relatively small payments (Knaul and others 2006; Schoenberg and others 2007; Thuan and others 2006).

Impoverishing health expenditure is defined as expenditure on health care that results in a household falling below the prevailing poverty line or deepening its impoverishment if it is already poor (Knaul, Wong, and ArreolaOrnelas 2012; Xu 2005). Such impoverishment is also linked to employment, because loss of income owing to ill health can drive households into poverty (Gertler and Gruber 2002).

Table 6.1 Indicators Used to Measure the Household Economic Burden of III Health

\begin{tabular}{|c|c|c|c|}
\hline Indicator & Definition & Advantages & Limitations \\
\hline $\begin{array}{l}\text { Catastrophic health } \\
\text { expenditure }\end{array}$ & $\begin{array}{l}\text { Total health care expenditure (out-of-pocket } \\
\text { costs) as a percentage of household } \\
\text { resources (O'Donnell and others 2007; Xu and } \\
\text { others 2003). The denominator, household } \\
\text { resources, is measured as discretionary } \\
\text { expenditure (also referred to as capacity to } \\
\text { pay or nonfood expenditure), total expenditure, } \\
\text { or household income. }\end{array}$ & $\begin{array}{l}\text { - Provides objective measure } \\
\text { of the drain on available } \\
\text { household resources caused } \\
\text { by health care expenditure } \\
\text { - Is the most commonly } \\
\text { used indicator and widely } \\
\text { endorsed }\end{array}$ & $\begin{array}{l}\text { - Has wide variation in the threshold and } \\
\text { denominator used and the categories of } \\
\text { health care expenditure included, which } \\
\text { makes it difficult to use as a benchmark } \\
\text { across studies } \\
\text { - Does not capture forgone care owing to } \\
\text { unaffordable health care costs } \\
\text { - Arbitrary threshold: implicitly assumes that } \\
\text { the given level of expenditure will impose } \\
\text { the same burden across the population }\end{array}$ \\
\hline $\begin{array}{l}\text { Impoverishing } \\
\text { health expenditure } \\
\text { (also referred } \\
\text { to as medical } \\
\text { impoverishment) }\end{array}$ & $\begin{array}{l}\text { The outcome when total health care } \\
\text { expenditure subtracted from baseline income } \\
\text { results in the household's income falling below } \\
\text { the prevailing poverty line (Wagstaff and van } \\
\text { Doorslaer 2003) }\end{array}$ & $\begin{array}{l}\text { Provides a measure of } \\
\text { the effect of illness on } \\
\text { the household's economic } \\
\text { well-being and potentially } \\
\text { the national economy }\end{array}$ & $\begin{array}{l}\text { - Does not account well for the } \\
\text { poorest households, for whom any } \\
\text { level of expenditure further entrenches } \\
\text { their poverty }\end{array}$ \\
\hline
\end{tabular}


Table 6.1 Indicators Used to Measure the Household Economic Burden of III Health (continued)

\begin{tabular}{|c|c|c|c|}
\hline Indicator & Definition & Advantages & Limitations \\
\hline $\begin{array}{l}\text { Economic hardship } \\
\text { or financial stress }\end{array}$ & $\begin{array}{l}\text { A measure of the potential consequences for } \\
\text { the household of health care expenditure. It } \\
\text { captures instances in which the household is } \\
\text { unable to meet the costs of essential payments } \\
\text { (housing, food, heating, child care, transport, } \\
\text { health care). It is most commonly defined as } \\
\text { an instance of missing any one of the specified } \\
\text { payments (Essue and others 2011). }\end{array}$ & $\begin{array}{l}\text { - Takes account of the } \\
\text { opportunity costs } \\
\text { associated with health care } \\
\text { expenditure and potential } \\
\text { economic consequences for } \\
\text { households }\end{array}$ & $\begin{array}{l}\text { - Has wide variation in the definition and } \\
\text { categories of expenses included, which } \\
\text { limits its generalizability } \\
\text { - Does not account well for instances in } \\
\text { which households were unable to meet } \\
\text { essential bills before the onset of illness } \\
\text { - Tends to be measured in cross-sectional } \\
\text { studies, which are unable to assess } \\
\text { the effect and recurrence of these } \\
\text { consequences over time }\end{array}$ \\
\hline Distressed financing & $\begin{array}{l}\text { A measure of the strategies used by the } \\
\text { household to pay for health care expenses, } \\
\text { often including savings, borrowed funds } \\
\text { (either through formal or informal loan or } \\
\text { through credit schemes), or sale of assets. It } \\
\text { is a descriptive measure that accounts for the } \\
\text { percentage of households using each of the } \\
\text { financing strategies (Kruk, Goldmann, and Galea } \\
\text { 2009; McIntyre and others 2006). }\end{array}$ & $\begin{array}{l}\text { - Accounts for the economic } \\
\text { consequences of health care } \\
\text { expenditure for household } \\
\text { economies } \\
\text { - Offers insights into } \\
\text { potentially effective informal } \\
\text { strategies for dealing with } \\
\text { health care costs }\end{array}$ & $\begin{array}{l}\text { - Has wide variation in the distressed } \\
\text { financing categories included, which limits } \\
\text { its generalizability } \\
\text { - Tends to be measured in cross-sectional } \\
\text { studies, which are unable to assess the } \\
\text { effect of using these strategies over time }\end{array}$ \\
\hline
\end{tabular}

Box 6.2

\section{Monitoring Universal Health Coverage: Achieving Financial Protection in Asia}

Universal health coverage entails everyone having access to needed health services without financial hardship. In the Western Pacific region, several countries have made progress toward achieving universal health coverage and protecting their populations from financial risk.

Country-specific studies on the equity of health service use and financial protection have been conducted in Mongolia (Tsilaajav, Nanzad, and Ichinnorov 2015), the Philippines (Ulep and dela Cruz 2013), and Vietnam (Minh and Phuong 2016). These studies examined health service use, out-of-pocket health expenditures, catastrophic health expenditure, impoverishing health expenditure, and their determinants over time. Data were from nationally representative surveys-socioeconomic or income and expenditure surveyscontaining information on health service use and health expenditure. The method used to calculate out-of-pocket, catastrophic, and impoverishing health expenditure followed the WHO methodology in all four countries (Xu 2005).

Annual household out-of-pocket health expenditures ranged from US $\$ 144$ in Mongolia to US $\$ 190$ in Vietnam. Medicines were a major component of out-of-pocket health expenditures in Mongolia and the Philippines. The average proportion of households that incurred catastrophic health expenditure (CHE) ranged from 0.9 percent in Mongolia to 2.3 percent in Vietnam (figure B6.2.1). Across expenditure quintiles, the proportion of households that incurred CHE increased in Mongolia and the Philippines but decreased in Vietnam as the expenditure quintile increased. Over time, the proportion of households incurring CHEs increased in the Philippines, but it fell in Mongolia and Vietnam.

Impoverishment resulting from health expenditures was highest in the lowest and second-to-lowest 


\section{Box 6.2 (continued)}

Figure B6.2.1 Proportion of Households with Catastrophic Health Expenditure in Selected Asian Countries, by Expenditure Quintile, Various Years

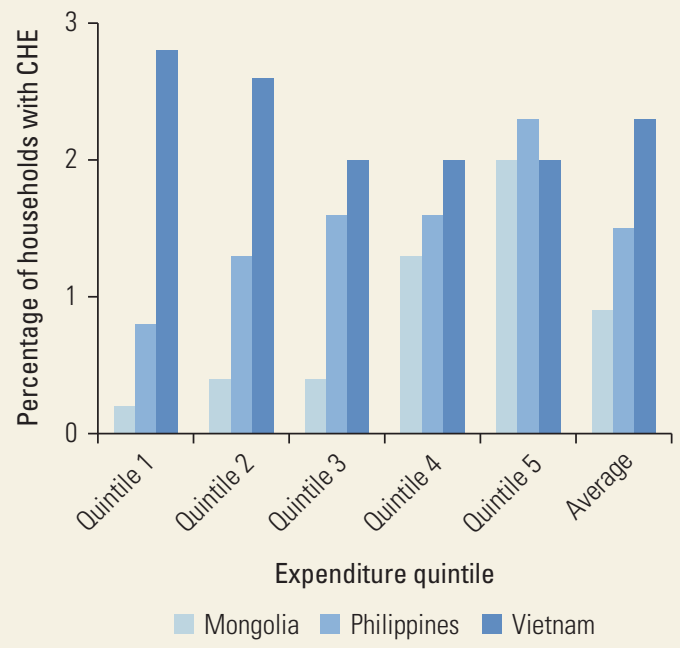

Sources: Tsilaajav, Nanzad, and Ichinnorov 2015, based on data from the 2012 Mongolia Household Socio-Economic Survey; Ulep and dela Cruz 2013, based on data from the 2012 Philippines Family and Income Expenditure Survey; Minh and Phuong 2016, based on data from the 2014 Vietnam Living Standards Survey.

expenditure quintiles, with Vietnam at 6.4 percent and Mongolia at 2.3 percent in the lowest expenditure quintile (figure B6.2.2).

Given differences in the data sources, methods, recall periods, and survey years, there are limitations comparing results across countries. However, these country-specific studies offer evidence for monitoring the
Figure B6.2.2 Proportion of Households Impoverished Owing to Health Expenditures in Selected Asian Countries, by Expenditure Quintile, Various Years

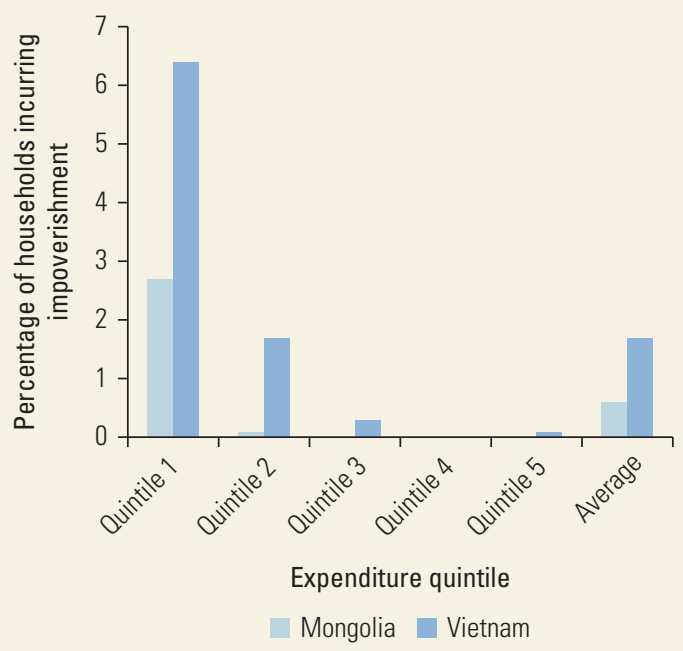

Sources: Tsilaajav, Nanzad, and Ichinnorov 2015, based on data from the 2012 Mongolia Household Socio-Economic Survey; Ulep and dela Cruz 2013, based on data from the 2012 Philippines Family and Income Expenditure Survey; Minh and Phuong 2016, based on data from the 2014 Vietnam Living Standards Survey. Note: For the Philippines, the national average proportion of impoverishment owing to health expenditures was 1.0 percent. Analyses by quintile are not available.

effects of universal health coverage, including health service use and financial protection. Further research and cross-country comparisons should focus on examining the shock and cumulative effects of the burden of health payments, particularly for poor and vulnerable populations and for households with members who are aging or have chronic diseases, where the effect of these outcomes is likely greater.
The poorest quintile of populations and older adults continue to be at greater risk than the general population (Goeppel and others 2016).

Much of the work in this field has focused on describing the burden associated with catastrophic and impoverishing health expenditure at the population level, illuminating the problem, and mobilizing support for population-wide initiatives such as universal health coverage. A limitation of the research to date is its use of population-based data that lack detailed indicators of the health status, including specific diseases, of individuals in the households under study. Research on the economic burden associated with particular diseases is needed to understand how specific diseases, especially those that are chronic, affect the economic well-being of households.

Population-based estimates of $\mathrm{CHE}$ using data from household surveys have been found to vary substantially from research in populations with chronic diseases. For instance, in Vietnam, population-level surveys found that 2.3 percent of all households had CHE in 2014 (box 6.2), whereas studies of individuals with diabetes (Smith-Spangler, Bhattacharya, and Goldhaber-Fiebert 2012), acute myocardial infarction (Jan and others 2016), and HIV/AIDS (Tran and others 2013) found that 8 percent, 38 percent, and 35 percent, respectively, had CHE. In China, population-level surveys found that 13 percent of all 
households had CHE in 2008 (Y. Li and others 2012), whereas studies of individuals with stroke (Heeley and others 2009), diabetes (Smith-Spangler, Bhattacharya, and Goldhaber-Fiebert 2012), and acute myocardial infarction (Jan and others 2016) found that 71 percent, 80 percent, and 15 percent, respectively, had CHE. This difference between population-level and diseaserelated estimates of CHE has also been found in both high-income countries (Essue and others 2011; Essue and others 2014; Schoen and others 2010) and other LMICs (Huffman and others 2011; Saito and others 2014; $\mathrm{Xu}$ and others 2003).

The household economic burden of ill health is not simply a population-level problem; it is also highly influenced by the disease course of individual conditions. Understanding variations in outcomes within populations can help decision makers identify the highest-risk populations, account for the ways in which different conditions affect patients and their households, and generate economic incentives for preventing and managing disease.

\section{PREVALENCE ESTIMATES OF CATASTROPHIC HEALTH EXPENDITURE ASSOCIATED WITH CHRONIC ILL HEALTH AND INJURIES IN LMICS}

This section analyzes the prevalence of CHE related to chronic ill health and injuries in LMICs and the way it differs among regions. The analysis is based on a systematic search of studies that reported rates of CHE associated with the treatment and management of seven conditions:

- Cancers: Breast, uterine, cervical, colorectal, mouth, pharynx, ovarian, stomach and tracheal, and bronchial or lung

- CVDs: CVD (undefined), angina, heart disease, acute coronary syndrome, acute myocardial infarction, stroke, cerebrovascular disease (undefined), and ischemic heart disease

- Chronic infectious diseases: HIV/AIDS, malaria, tuberculosis, and hepatitis B

- Endocrine diseases: Diabetes and endocrine disease (undefined, but not diabetes)

- Injuries: Injuries caused by assault, blunt objects, burns, falls, road traffic accidents, and sharp objects

- Renal diseases: Chronic kidney disease and kidney disease (undefined).

- Respiratory diseases: Asthma, chronic obstructive pulmonary disease, and pulmonary disease (undefined).
Table 6.2 Global Burden of Disease, by Category of Disease, 2012

\begin{tabular}{lc}
\hline Disease category & $\begin{array}{c}\text { Percentage of total global } \\
\text { burden of disease }\end{array}$ \\
\hline Infectious diseases & 15.8 \\
Cardiovascular diseases & 14.4 \\
Injuries & 11.1 \\
Cancers & 8.2 \\
Respiratory diseases & 5.0 \\
Endocrine diseases & 2.2 \\
Renal diseases & 1.1 \\
Total & 57.8 \\
\hline
\end{tabular}

Source:WHO 2014

a. Measured using disability-adjusted life year.

We initially included maternal, infant, and childhood conditions and mental illnesses in the search, but excluded them from the analysis, because too few studies reported rates of $\mathrm{CHE}$ for these conditions. From a broader perspective, the remaining seven categories of disease constitute almost 60 percent of the total global burden of disease, as shown in table 6.2.

\section{Methodology}

This discussion is based on a systematic search of studies that reported rates of CHE associated with the treatment and management of chronic ill health and injuries. The detailed search strategy and the equations used for the calculations are described in online annex $6 \mathrm{~A}$, along with the characteristics of the studies identified in the search.

One issue that arose is the lack of consensus in the measurement of CHE. A commonly used approach is to measure the household's total annual expenditure on health care or health-related expenses (for example, transport) as a proportion of the household's resources, measured in terms of income, expenditure, or consumption (O'Donnell and others 2007). Household resources as the denominator in this equation may involve a measure of either nondiscretionary expenditure (Wagstaff and van Doorslaer 2003) or capacity to pay (Xu and others 2003), both of which define CHE in terms of nonfood expenditure. In this analysis, we note the CHE definitions and thresholds used in each study but nonetheless include each as essentially the same outcome when calculating the prevalence of $\mathrm{CHE}$ associated with each condition.

\section{Summary of Findings}

The systematic search identified 41 studies ( 42 published papers) that reported rates of disease-related CHE. 
Most studies used a cross-sectional design (30), recruiting either a convenience sample (22) or a random sample (18) from either a health care facility or a hospital (26) or from households in the community (14); 1 study used administrative data. The studies were conducted between 1997 and 2013, with 14 conducted between 2010 and 2013. Of these 41 studies, 7 were conducted in high-income countries (2 in Australia, 1 in Greece, 2 in the Republic of Korea, and 2 in the United States). This analysis focuses only on LMICs.
Most of the studies were conducted in middle-income countries, clustered in South and East Asia; the greatest numbers were conducted in China (8) and India (6) (map 6.1). Endocrine diseases and CVDs were the most studied conditions (table 6.3), which is reasonably consistent with the 20 leading causes of disease burden (Global Burden of Disease Study 2013 Collaborators 2015). Data coverage from the systematic search was best for countries in the upper-middle-income group; the greatest gaps were for research on renal and respiratory diseases (see online annex 6A, table 6A.4).

\section{Map 6.1 Density of Studies on Disease-Related Catastrophic Health Expenditure}

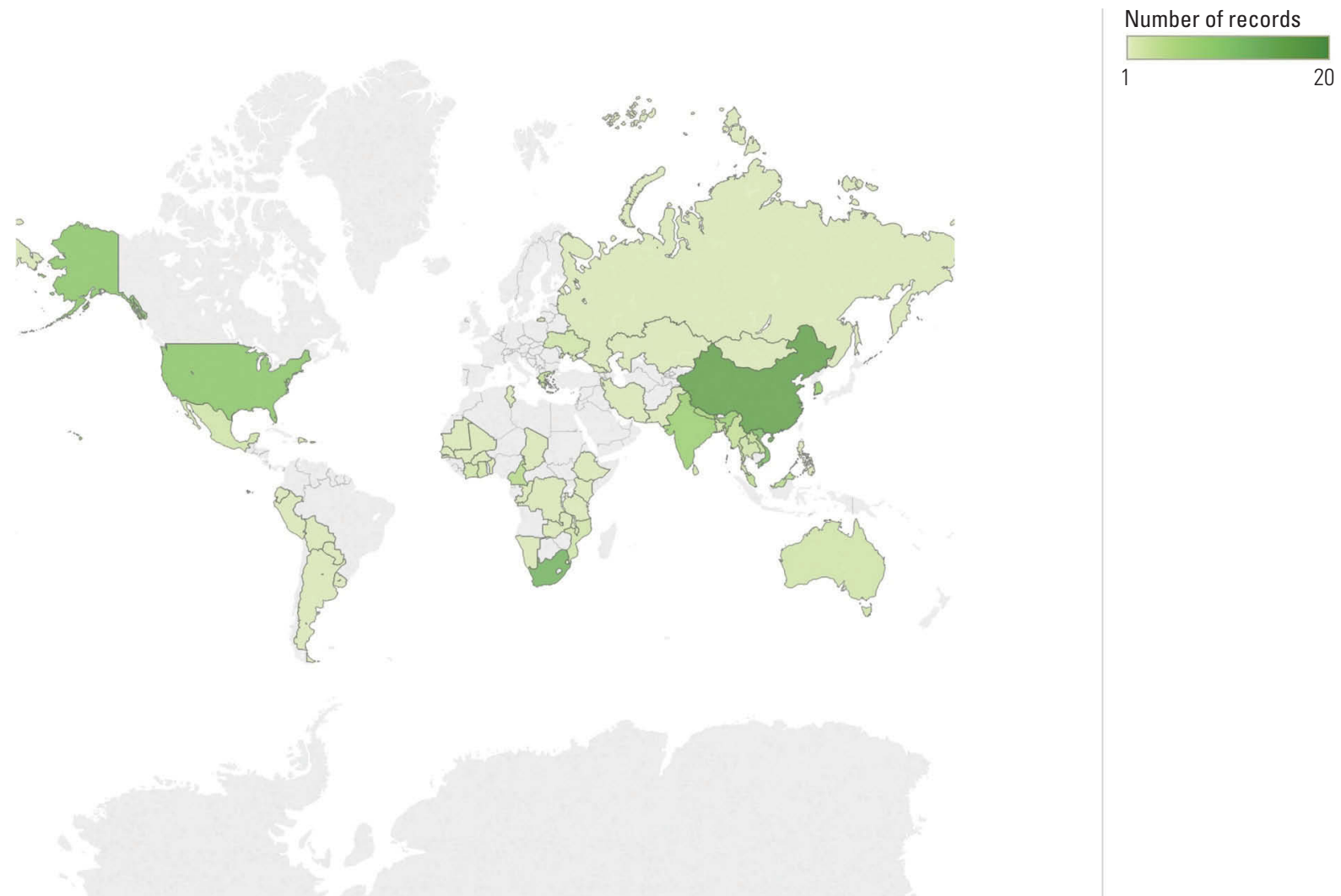

Note: The map includes studies found for all country income categories. For multicountry studies, each country is represented in the figure so the total number of studies depicted exceeds the number of studies identified in the systematic search.

Table 6.3 Density of Conditions for the Study of Disease-Related Catastrophic Health Expenditure, by Country Income Group

\begin{tabular}{lccc}
\hline & \multicolumn{3}{c}{ Country income group } \\
\cline { 2 - 4 } Disease & Low-income & Lower-middle-income & Upper-middle-income \\
\hline Endocrine diseases & 7 & 17 & 10 \\
Cardiovascular diseases & 5 & 9 & 7 \\
Cancers & 1 & 5 & 5 \\
\hline
\end{tabular}


Table 6.3 Density of Conditions for the Study of Disease-Related Catastrophic Health Expenditure, by Country Income Group (continued)

\begin{tabular}{lccc}
\hline & \multicolumn{3}{c}{ Country income group } \\
\cline { 2 - 4 } Disease & Low-income & Lower-middle-income & Upper-middle-income \\
\hline Chronic infectious diseases & 3 & 4 & 6 \\
Injuries & 1 & 2 & - \\
Maternal, infant, and childhood & - & 2 & 1 \\
conditions & - & - & 1 \\
Renal diseases & - & 1 & - \\
Respiratory diseases & - & - & - \\
Mental illnesses & - & 1 & 1 \\
Multiple conditions & & & \\
\hline
\end{tabular}

Note: The number in each cell is the count of studies of each condition identified in the review. Some studies included multiple conditions and different countries, and thus the total count in this table exceeds the total number of articles reviewed. $-=$ none.

All studies collected data on out-of-pocket payments for direct medical expenses, although the categories of expenses collected varied somewhat. Where specified, most studies collected data on medicines (30), and more than half collected data on hospitalizations (24) and medical consultations (27). Nonmedical costs (travel, accommodation, care expenses) were taken into account in 19 studies and lost productivity in 4 studies.

CHE was most commonly measured in terms of a household's capacity to pay, defined as total expenditure net of food expenses (Xu and others 2003), followed by income thresholds and total expenditure (figure 6.2). By condition category, the ranges in CHE rates were as follows:

- Cancers: 6.2 percent (cancer, undefined, Republic of Korea) to 67.9 percent (cancer, undefined, the Islamic Republic of Iran)

- CVDs: 0.05 percent (heart disease, Nepal) to 84.3 percent (CVD, Tanzania)

- Chronic infectious diseases: 7.1 percent (malaria, South Africa) to 90.0 percent (HIV/AIDS, the Lao People's Democratic Republic)

- Endocrine diseases: 1.0 percent (diabetes, Nepal) to 26.6 percent (diabetes, Ecuador)

- Injuries: 0.8 percent (injury, undefined, Nepal) to 46 percent (road traffic injury, India).

- Maternal, infant, and childhood conditions: 1.0 percent (rotavirus, Malaysia) to 44.8 percent (rotavirus, Bolivia)

- Mental illnesses: 5.5 percent (depressive disorders, India)

- Renal diseases: 9.8 percent (kidney disease, the United States) to 71.0 percent (chronic kidney disease, Australia)

- Respiratory diseases: 3.0 percent (asthma, Myanmar) to 46.0 percent (chronic obstructive pulmonary disease, Australia).
Rates of CHE from studies based on samples from hospitals or health care facilities were significantly higher than those from studies based on samples from households or communities for each World Bank income category (low-income: $\overline{\mathrm{x}}$ diff, 56.2; $\mathrm{t}=5.00, p=0.007$; lower-middle-income: $\overline{\mathrm{x}}$ diff, $27.1 ; \mathrm{t}=4.97, p<0.0001$; upper-middle-income: $\bar{x}_{\text {diff, }} 26.5 ; t=3.75, p<0.0001$ ). This difference is not surprising, because hospitals are not an unbiased source of population data on health expenditure.

Overall, across all LMICs, the largest population experiencing CHE comprised persons with renal diseases (187.7 million), followed by CVDs (138.4 million), chronic infectious diseases (101.9 million), endocrine diseases (46.0 million), cancers (14.3 million), respiratory diseases ( 9.6 million), and injuries ( 0.9 million). In upper-middle-income countries, the largest population experiencing $\mathrm{CHE}$ comprised persons with renal diseases (100.6 million), followed by CVDs (78.2 million), chronic infectious diseases (74.2 million), endocrine diseases (22.4 million), cancers (11.9 million), respiratory diseases (8.2 million), and injuries (0.5 million). In lower-middle-income countries, the largest population experiencing CHE comprised persons with renal diseases (83.3 million), followed by CVDs (59.9 million), endocrine diseases (23.3 million), and chronic infectious diseases (6.2 million). In low-income countries, chronic infectious diseases were associated with the greatest burden of CHE (21.4 million), followed by renal diseases (3.8 million), CVDs ( 0.4 million), and endocrine diseases (0.3 million) (figure 6.3).

In a sensitivity analysis, we calculated the populations with CVD-related CHE using only studies that measured CHE defined as health care expenditures in excess of 40 percent of the household's capacity to pay. We found 
Figure 6.2 Catastrophic Health Expenditure Rates, by Source and Disease Category

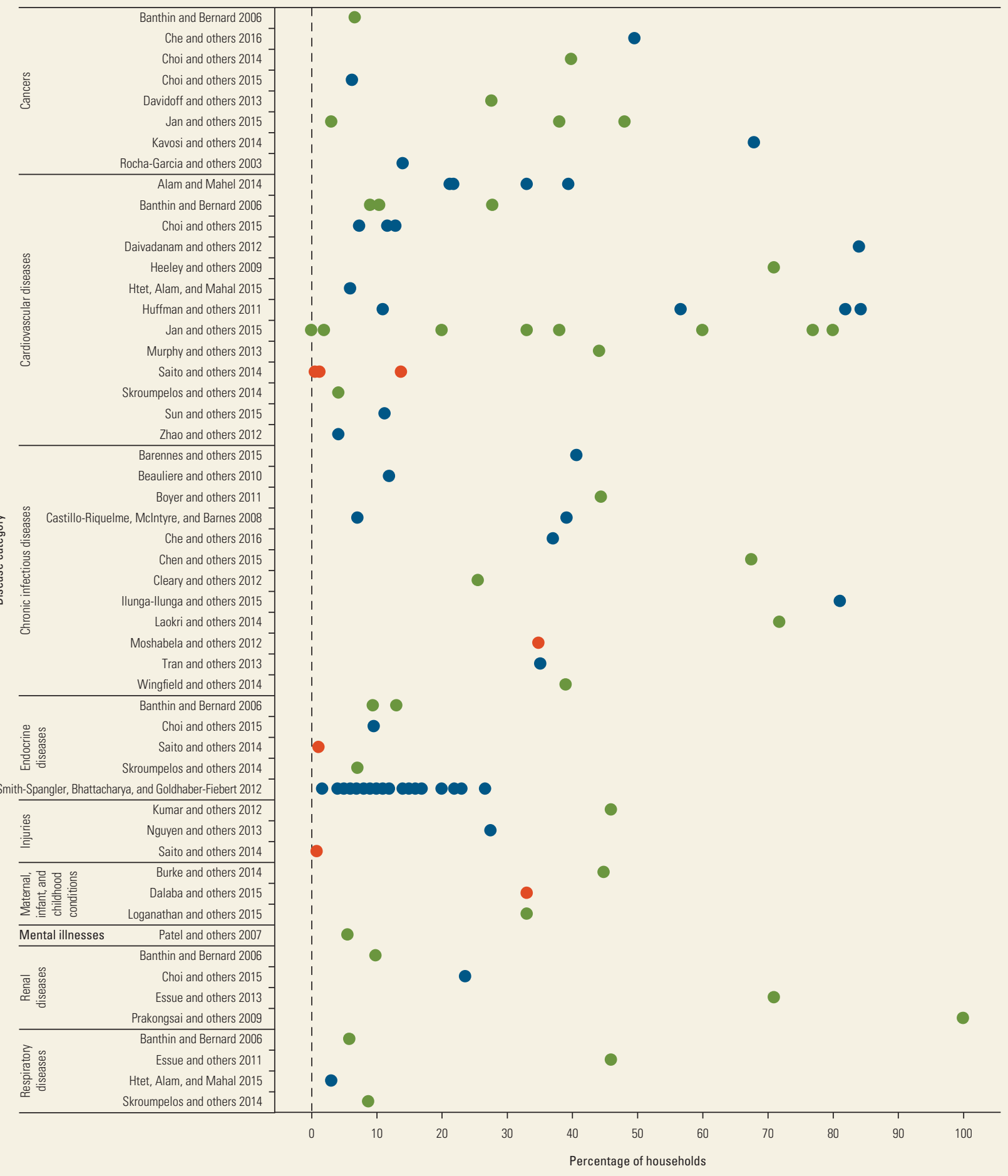

Capacity to pay $(>30 \%)$

Note: For most studies, capacity to pay was defined as in Xu and others (2003). Different data were used to calculate the denominator for each catastrophic health expenditure (CHE) outcome (capacity to pay, income, total expenditure), so standardizing the estimates to a common benchmark was not possible. Each threshold of CHE was used to denote an event of catastrophic significance for the individual patient or household under investigation. Because they are linked through a common conceptual construct and as a way to allow for comparisons of the burden of CHE across the range of diseases, the varying thresholds used in each study are noted here but are treated as essentially the same outcome in this analysis. The CHE rate of 100 percent, reported for renal replacement therapy in Thailand (Prakongsai and others 2009), was excluded from the calculation of the case catastrophe rate for renal diseases. 
no significant difference in case catastrophe rates and the prevalence of CVD-related CHE for all regions when the analysis was limited to studies using this common definition (table 6.4).

Figure 6.4 summarizes the case catastrophe rate relative to the prevalence of each category of condition. The case catastrophe rate is the population-weighted average $\mathrm{CHE}$ rate for each condition and World Bank income category. The large estimated burden of $\mathrm{CHE}$ predicted to be associated with renal diseases is explained by the high prevalence of disease and the high case catastrophe rate in populations with prevalent disease; renal diseases affect many individuals and are associated with a high burden because of the type of care required. Those circumstances also apply to chronic infectious

Figure 6.3 Estimated Population with Catastrophic Health Expenditures Related to Chronic III Health and Injuries, by Disease Category and Country Income Group

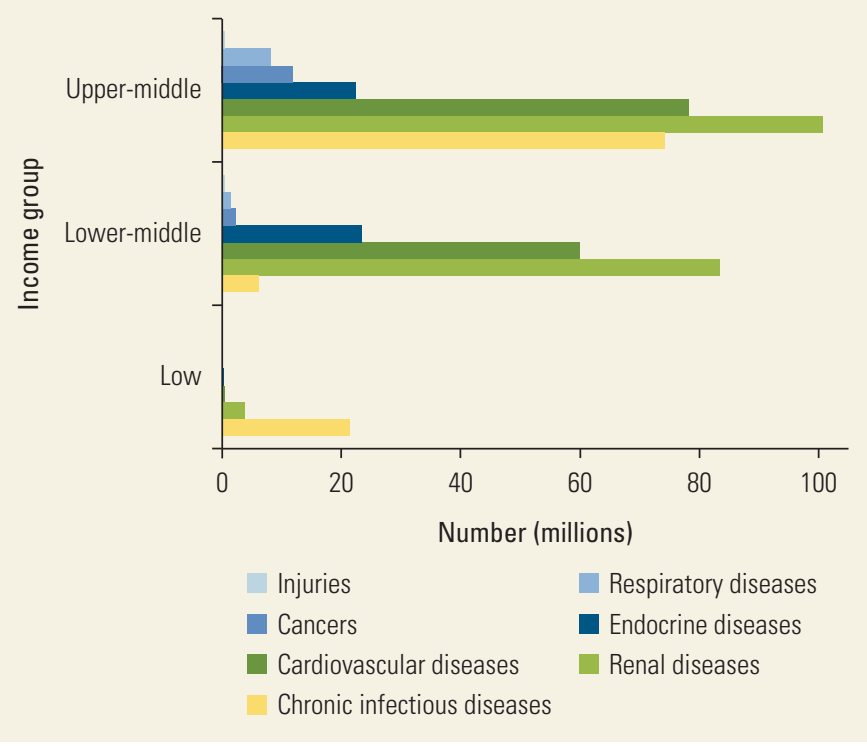

diseases and CVDs. The case catastrophe rate for injuries is lower in low-income countries than in the other country income groups, despite the high prevalence of injuries. This variation is in contrast to cancers, where the prevalence of disease is relatively lower, so the main driver of the prevalence of cancer-related CHE is the high case catastrophe rate associated with the treatment and management of these conditions in all national income groups.

\section{OTHER MEASURES OF HOUSEHOLD-LEVEL ECONOMIC EFFECT OF CHRONIC ILL HEALTH AND INJURIES IN LMICS}

In this section, we report data from a review of the disease-related burden associated with indicators other than CHE: impoverishing health expenditure, productivity effects, distressed financing, and treatment discontinuation (table 6.1). These indicators supplement and complement the measurement of CHE, because they help describe the effect of ill health on a household's economic well-being (Moreno-Serra, Millett, and Smith 2011; Ruger 2012), including the way households respond, opportunity costs, and the effect of forgone income. The indicators also tend to focus on the effect of ill health on the poorest of the poor, who may be omitted from other measures, including $\mathrm{CHE}$, because their income is so low.

We did not estimate the disease-related prevalence associated with each indicator, as done for CHE, given insufficient data. We thus restrict this discussion to a descriptive analysis. The populations affected by these other measures are not mutually exclusive, so there is significant overlap with the population estimates of disease-related CHE reported in the previous section.

A systematic review of 47 LMIC studies was conducted to evaluate the household economic effect of NCDs.

Table 6.4 Sensitivity Analysis: Comparison of Case Catastrophe Rates and the Projected Population with Cardiovascular Disease-Related Catastrophic Health Expenditure

\begin{tabular}{|c|c|c|c|c|}
\hline \multirow[b]{2}{*}{$\begin{array}{l}\text { Country } \\
\text { income level }\end{array}$} & \multicolumn{2}{|c|}{ All definitions of $\mathrm{CHE}^{\mathrm{a}}$} & \multicolumn{2}{|c|}{$\begin{array}{c}\text { Definition limited to CHE as }>40 \% \text { of } \\
\text { household's capacity to pay }\end{array}$} \\
\hline & $\begin{array}{c}\text { Case catastrophe } \\
\text { rate }(\%)\end{array}$ & $\begin{array}{l}\text { Population with } \\
\text { CVD-related CHE }\end{array}$ & $\begin{array}{c}\text { Case catastrophe } \\
\text { rate }(\%)\end{array}$ & $\begin{array}{l}\text { Population with CVD- } \\
\text { related CHE }\end{array}$ \\
\hline Low & 8.1 & 162,163 & 6.6 & 131,398 \\
\hline Lower-middle & 21.2 & $22,065,683$ & 21.0 & $21,829,842$ \\
\hline Upper-middle & 51.9 & $78,153,956$ & 46.9 & $70,665,614$ \\
\hline
\end{tabular}

Note: $\mathrm{CHE}=$ catastrophic health expenditure; $\mathrm{CVD}=$ cardiovascular disease.

a. Catastrophic health expenditure was defined as (a) more than 40 percent of household capacity to pay (or nonfood expenditure); (b) more than 10 percent of household expenditure; (c) more than 40 percent of effective income; or (d) more than 30 percent of household income in the published studies. 
Figure 6.4 Rate of Catastrophic Health Expenditure Relative to Average Prevalence of Each Condition, by Country Income Group

\section{a. Low income}

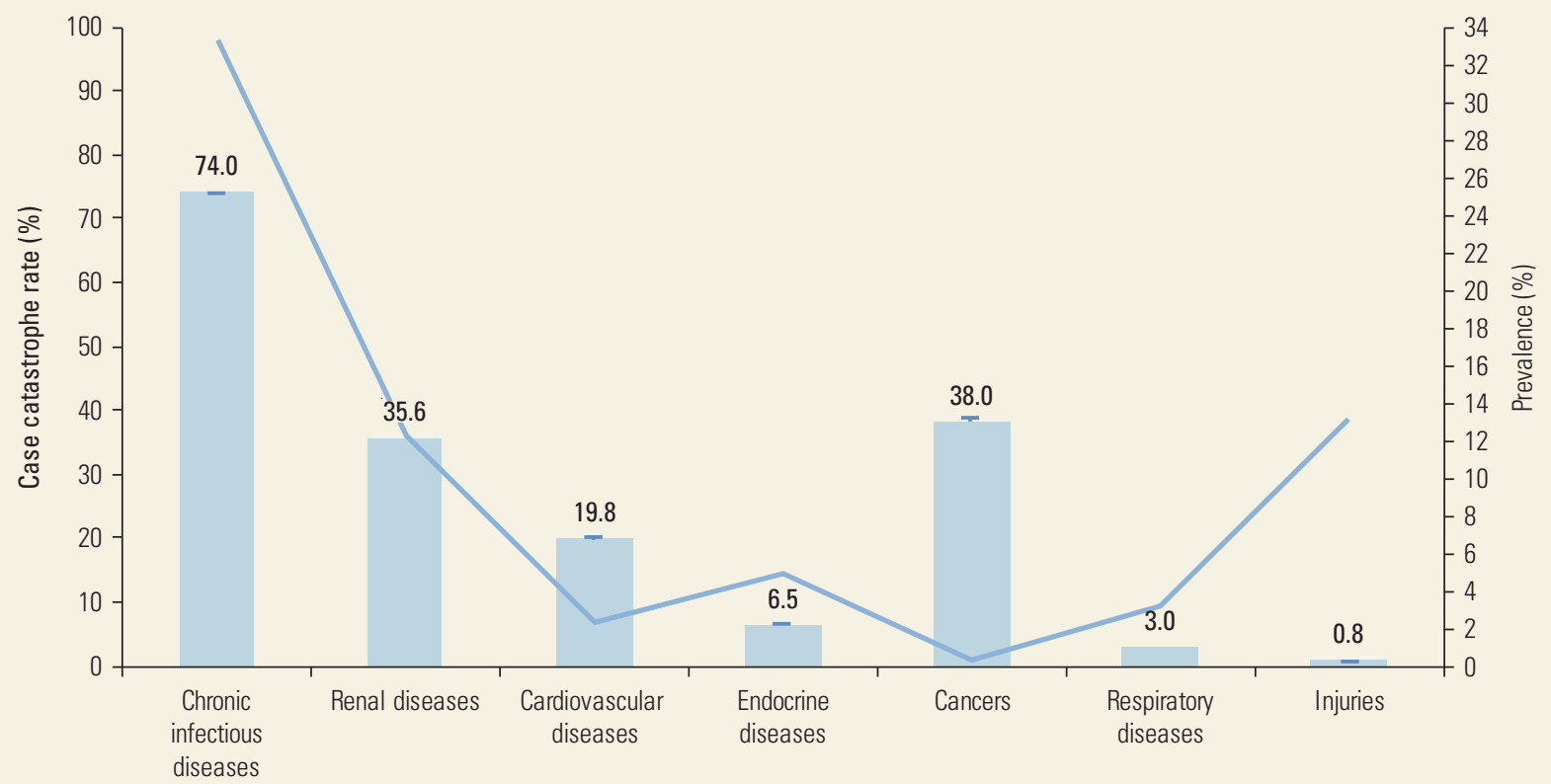

b. Lower-middle income

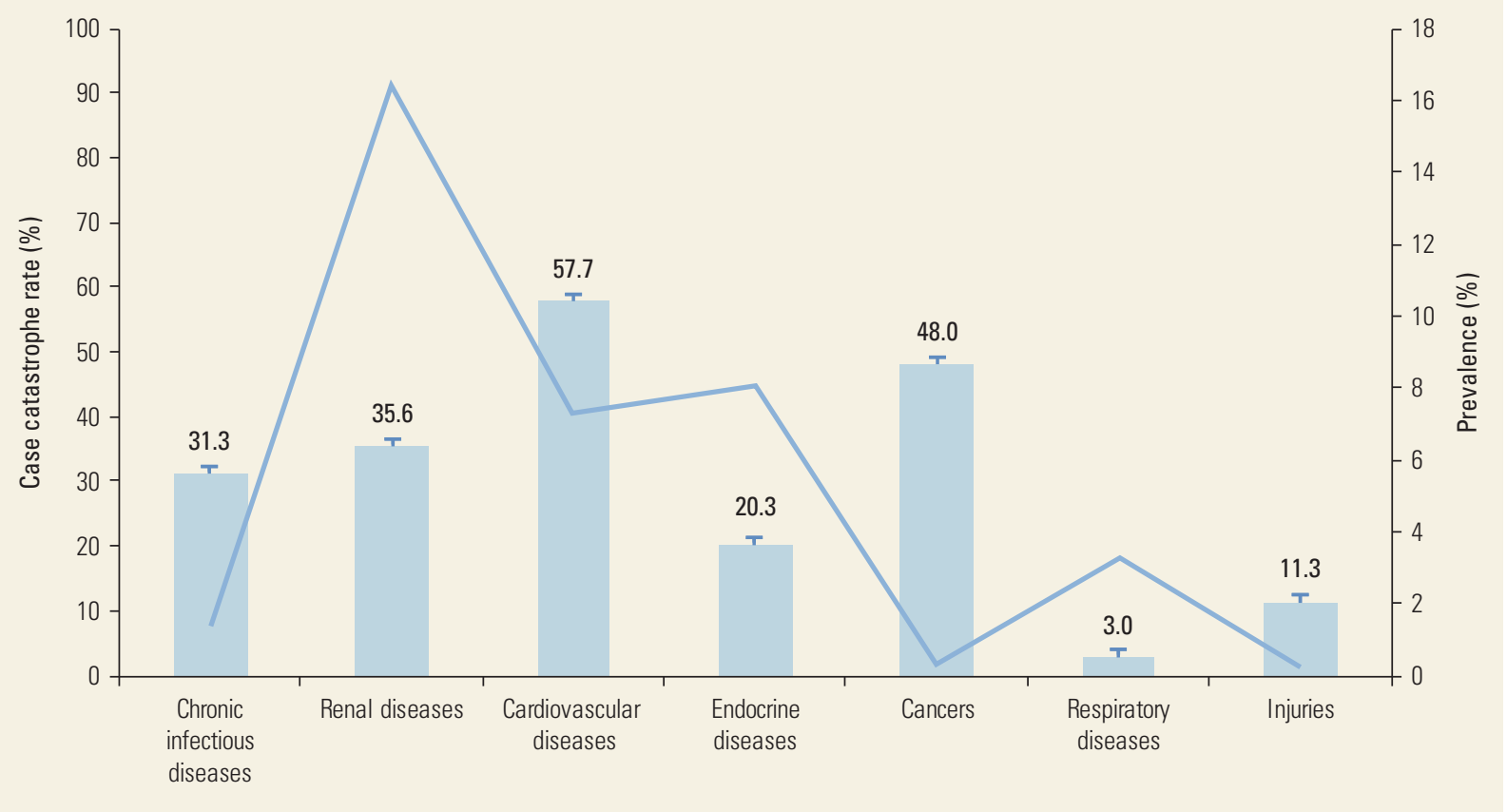

figure continues next page 


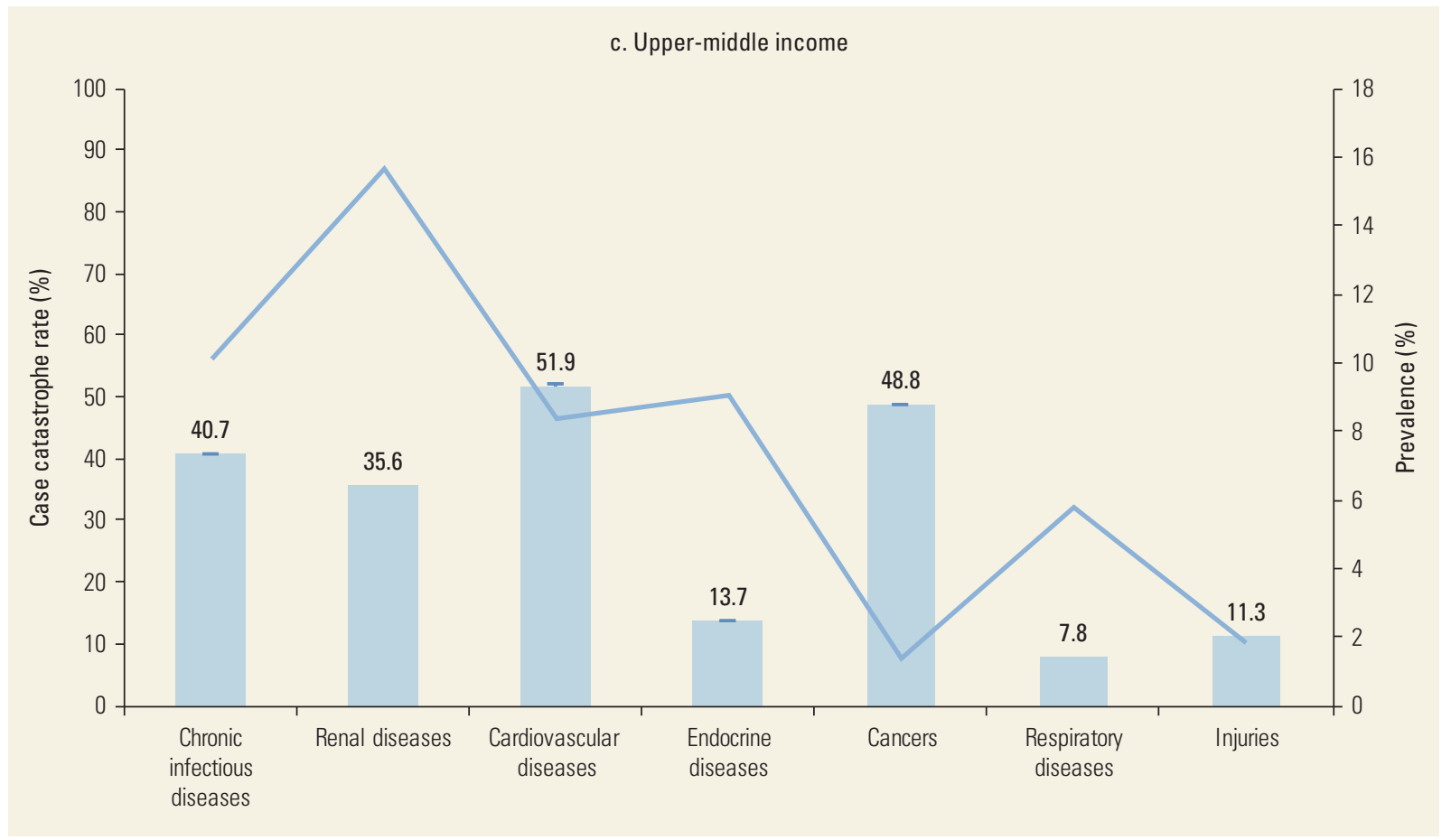

Note: The blue stacks correspond to the left-hand axis and illustrate the weighted case catastrophe rate (\%) for each condition, in each country income category. The blue line corresponds to the right-hand axis and illustrates the average weighted prevalence of each condition, in each country income category. The t-bars illustrate the 95 percent confidence intervals for the weighted case catastrophe rates, in cases where they could be calculated.

The methods are described in annex 6B. The systematic review synthesized evidence from studies in populations of patients with NCDs. Of the 47 studies identified, 11 overlapped with the studies identified in the previously described systematic search. CHE was the most commonly measured outcome. However, several studies also incorporated additional indicators of the economic burden of NCDs on households.

\section{Impoverishing Health Expenditure}

Although impoverishing health expenditure is now routinely investigated in many population-based studies, including alongside $\mathrm{CHE}$, few studies have investigated the disease-related burden. In the review of NCD studies in LMICs, seven studies measured the rate of NCD-related impoverishing health expenditure. Across the studies, the rate of impoverishment was below 15 percent. However, in a study conducted among Chinese people experiencing hypertension, stroke, or coronary heart disease, the incidence of impoverishment hovered around 50 percent and was not statistically different after implementation of the national health insurance scheme (J. Wang and others 2012; figure 6.5).

\section{Productivity Changes}

Six studies examined the effect of chronic diseases, particularly CVDs, on an individual's capacity to maintain usual working status. In some settings, more than 80 percent of patients affected by CVDs reported having to limit their usual work activities and more than 60 percent reported having to work less. In addition to the effect on individuals' productivity, one study conducted across four countries also found that family members had to increase their work activities or find new work. Whether such changes in productivity are different for households that are experiencing disease than for those that are not is unclear. For instance, a study conducted in India found that the decreases in workforce participation of individuals experiencing angina were not significantly different from those of households not experiencing disease (Alam and Mahal 2014).

By contrast, a study by Zhang, Chongsuvivatwong, and Geater (2006) found that the presence of major chronic illness resulted in a 6.5 percent decrease in the probability of remaining in paid work in China. Similarly, although the workforce participation rates of canceraffected households were significantly lower than those 
Figure 6.5 Proportion of Households with Noncommunicable Diseases Experiencing Impoverishing Health Expenditure, by Disease Category and Country Income Group

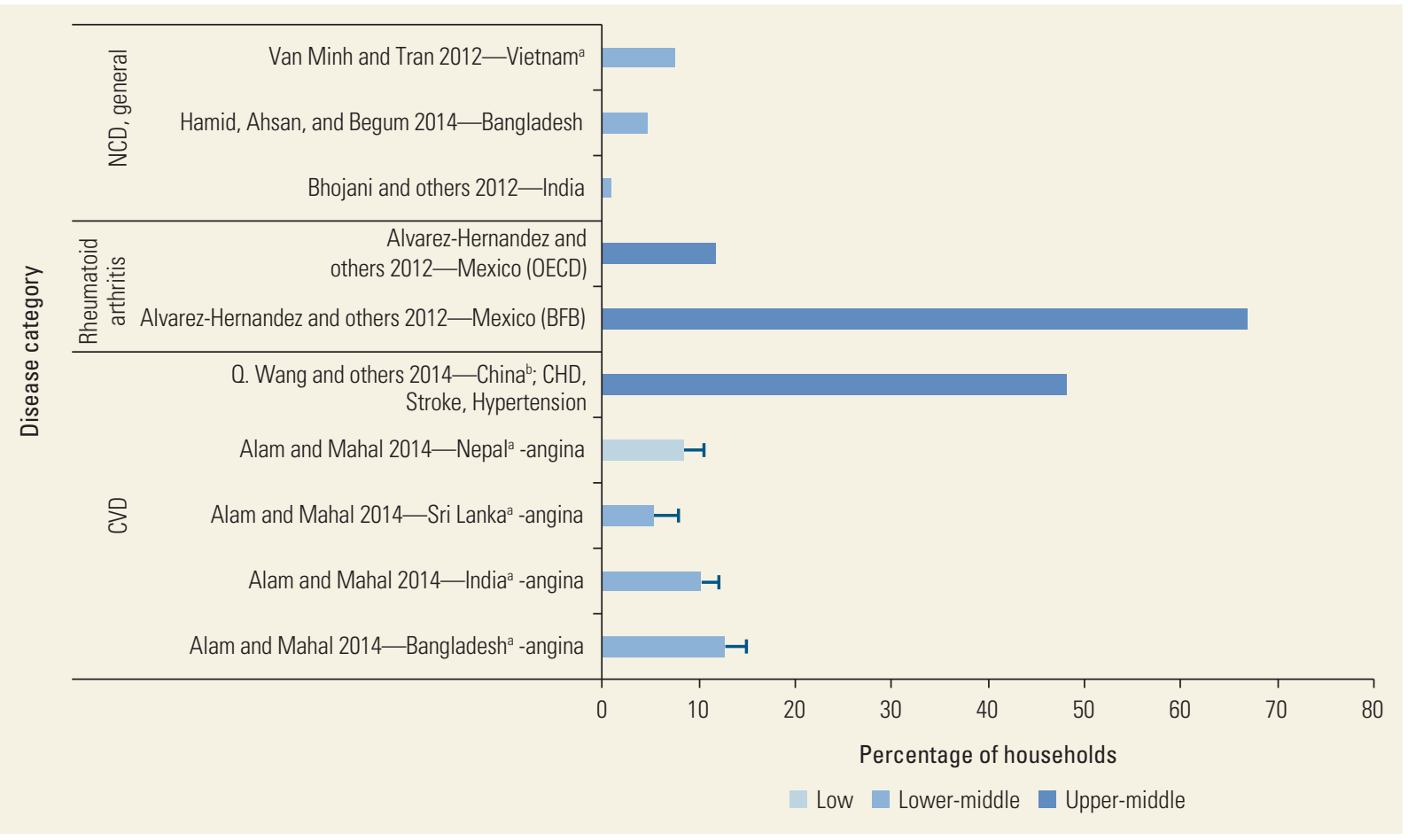

Note: $\mathrm{BFB}=$ the proportion of households was calculated using the basic food basket method as the threshold; $\mathrm{CVD}=$ cardiovascular disease; $\mathrm{NCD}=$ noncommunicable disease; $\mathrm{OECD}=$ the proportion of households was calculated using the Organisation for Economic Co-operation and Development definition for poverty as the threshold. The t-bars illustrate the 95 percent confidence intervals for the estimate (percentage of households), in cases where they could be calculated.

a. Statistically significant difference was found between those with and those without disease.

b. No statistically significantly difference was found between those with and those without disease

of non-cancer-affected households, when an individual with cancer was removed from consideration, there were no discernible differences between households with and without disease. In spite of this finding, although the incidence of work-related changes was captured, very few studies valued these changes in monetary terms (figure 6.6).

\section{Distressed Financing}

Six studies attempted to quantify the financing strategies used to pay for health care for NCDs, including CVDs and cancers. Whereas in one study, almost all households relied on savings to finance their health care (Bhojani and others 2013), more commonly, households reported selling assets or calling on family and friends. This circumstance was especially evident in the most socioeconomically disadvantaged households (Huffman and others 2011). The few studies that compared households with and without disease found that these strategies were needed more often in households confronted with chronic disease (Alam and Mahal 2014; figure 6.7).

\section{Treatment Discontinuation}

An obvious consequence of unaffordable health care is treatment attrition or abandonment (Arora, Eden, and Pizer 2007; Israels and others 2008; Jan and others 2015). For example, in a study of CVD patients in Argentina, China, India, and Tanzania, up to 99 percent of households reported not taking CVD medications because of the cost (Huffman and others 2011). Similarly, in a study conducted among diabetes-affected households across 35 LMICs, less than 30 percent of individuals were in possession of medications in 71 percent of countries (SmithSpangler, Bhattacharya, and Goldhaber-Fiebert 2012). This outcome was not routinely examined within studies of NCD-related CHE. The relationship between $\mathrm{CHE}$ and treatment discontinuation is important for discerning whether trends in health care expenditure, and CHE in particular, have been affected by the discontinuation or avoidance of necessary health care by households or individuals when faced with unaffordable costs. This is highly relevant for the treatment of chronic conditions in cases where treatment attrition or abandonment can lead to further deterioration of health and higher health care costs. 
Figure 6.6 Proportion of Households with Noncommunicable Diseases Reporting Productivity Effects, by Disease Category and Country Income Group

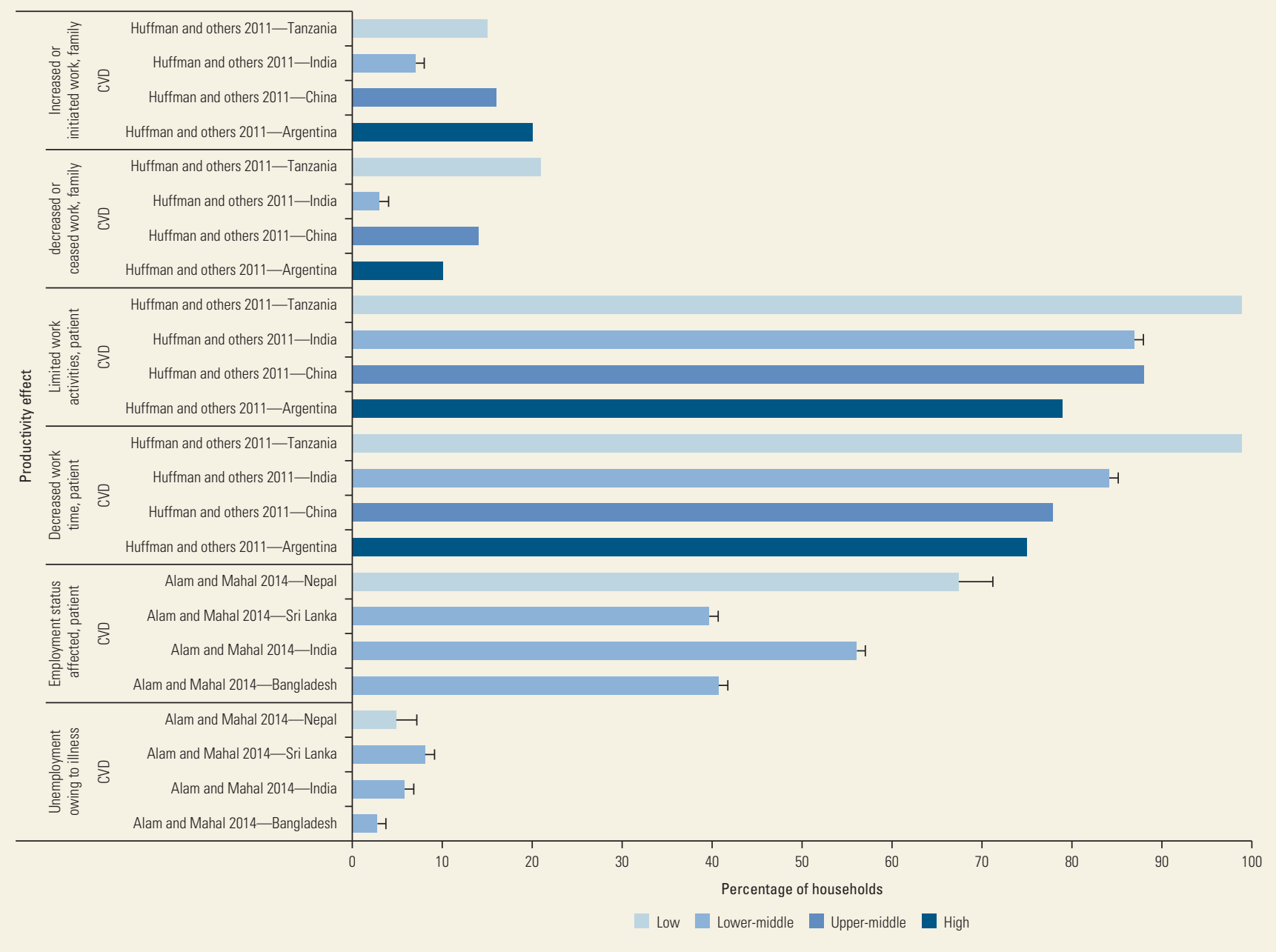

Note: $\mathrm{CVD}=$ cardiovascular disease. The t-bars illustrate the 95 percent confidence intervals for the estimate (percentage of households), in cases where they could be calculated.

\section{DISCUSSION}

Patients with chronic conditions and injuries in LMICs face a substantial economic burden as a result of paying for health care. Chronic conditions such as renal, cardiovascular, and endocrine diseases account for the largest populations with CHE. However, in low-income countries individuals with chronic infectious diseases such as HIV/AIDS, tuberculosis, and malaria are the largest populations with $\mathrm{CHE}$.

The factors underlying these estimates are both prevalence of disease and rates of $\mathrm{CHE}$ associated with each category of conditions. For example, the comparatively higher burden associated with renal conditions in all settings is likely explained by the fact that renal disease is an end product of other NCDs, notably diabetes and CVDs. These precursory NCDs are undertreated (Khatib and others 2016; Lange and others 2004; W. Li and others 2016), and the costs associated with treating renal disease are high, including the costs of medicines and dialysis (Teerawattananon and others 2016; White and others 2008).

The high costs of treatment for different conditions are due to factors such as place of treatment and out-ofpocket costs for different types of treatment. For example, out-of-pocket costs associated with hospitalization for an acute event may be high, as for conditions such as stroke in China (Heeley and others 2009) and acute myocardial infarction in both China and India (Jan and others 2016). However, paying for treatment that is required on an ongoing basis can also lead to a high cost burden, whether the payments are marginal, such as paying for medicines or, at a more extreme end, the cost of regular dialysis for managing chronic kidney 
Figure 6.7 Proportion of Households with Noncommunicable Disease Using Distressed Financing Strategies, by Disease Category and Country Income Group

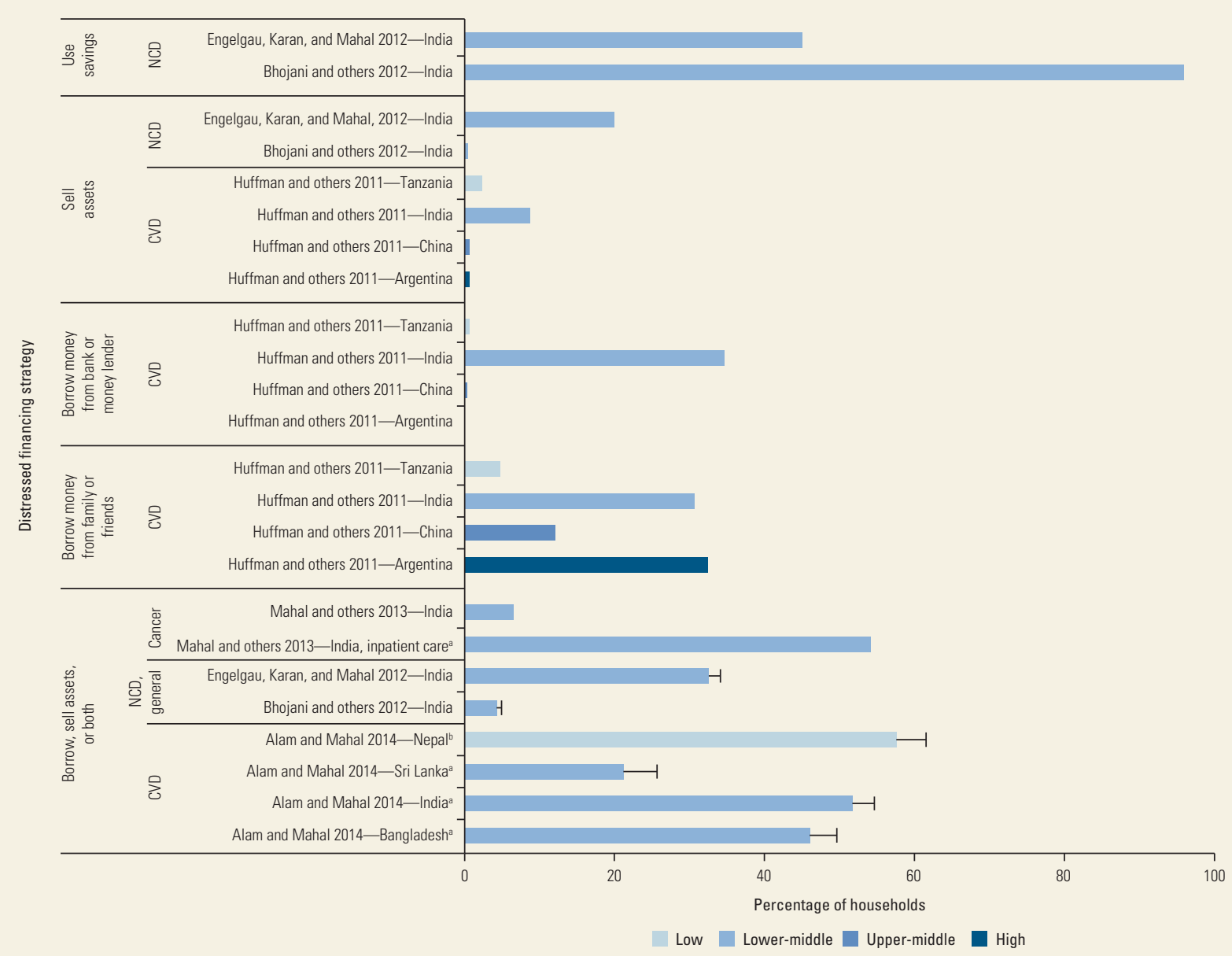

Note: $\mathrm{CVD}=$ cardiovascular disease; NCD = noncommunicable disease. The t-bars illustrate the 95 percent confidence intervals for the estimate (percentage of households), in cases where they could be calculated.

a. Statistically significant difference was found between those with and those without disease.

b. No statistically significantly difference was found between those with and those without disease

disease (Prakongsai and others 2009; Ramachandran and Jha 2013).

Endocrine diseases and injuries in low-income settings both have relatively high prevalence but comparatively lower rates of CHE. For injuries, although the costs associated with treating an acute episode in either a hospital or a community health setting may be high, ongoing health care costs after recovery may be minimal. However, if the severity of the injury affects the individual's ability to continue in paid work, the household may still experience negative economic consequences from this loss of income, which is not captured in the CHE measures. In addition, in low-income countries, survival rates from injuries such as those resulting from traffic accidents are lower (Dalal and others 2013), so the risk of incurring $\mathrm{CHE}$ is lower.

HIV/AIDS, like other long-term illnesses, is associated with a relatively higher rate of CHE, likely because of the ongoing costs of medicines in settings where access to free antiretroviral treatment is suboptimal. For cancers, the prevalence of disease is relatively lower, both overall and in each country income category, but the cost burden is comparatively high because of treatment costs associated with chemotherapy, radiation, and surgery (Aggarwal and Sullivan 2014; Pramesh and others 2014).

In the context of an increasing prevalence of multiple morbidity, estimated at 7.8 percent in LMICs (Afshar and others 2015), such high levels of expenditure associated 
with one condition would potentially compromise an individual's ability to afford the range of care that is required when faced with multiple morbidity. This circumstance could lead to trade-offs, including a prioritization of treatment for acute conditions over chronic care, especially in cases where conditions are asymptotic.

There is substantial variation in the cost burden and risk of $\mathrm{CHE}$ associated with chronic conditions and injuries in cases where expenditures are often repeated and continuous. Curbing the rates of $\mathrm{CHE}$ will require targeting financial risk protection to cover elements of treatment for conditions with high risk of $\mathrm{CHE}$ and high prevalence, such as renal diseases and CVDs. In lowincome settings, additional protection might be required for major infectious diseases. Identifying the elements of treatment that impose the greatest cost burden, which may be common across various disease categories, will help achieve the greatest gains in mitigating the risk of $\mathrm{CHE}$ at a population level.

Global work, especially from the WHO, has highlighted the significant household economic burden that is associated with accessing and using health care services, particularly in LMICs. In addition, it has been a driving force in efforts to implement effective financial protection mechanisms to mitigate this burden. Comparability of our results with WHO global estimates of the prevalence of CHE depends on the relative distribution of chronic diseases, injuries, and comorbidity within the population-level data used to generate the estimates. The rates of $\mathrm{CHE}$ are much higher when measured in the population with disease than in the population as a whole. Our analysis, which uses samples of persons with disease, shows that many more people in LMICs and globally are at risk of CHE than previously estimated (Xu and others 2007). Furthermore, the estimates reported here for each category of conditions are not cumulative, given the high prevalence of multiple morbidity overall and the overlapping of comorbid conditions between disease categories included in this analysis.

\section{LIMITATIONS OF THE RESEARCH}

\section{Comparability among Countries and Health Care System Contexts}

The economic burden associated with health care expenses is context specific. Differences in the financing and service provision arrangements among health care systems in each country may influence the populations and the breadth of services covered, the mix of private and publicly funded services, and the out-of-pocket costs associated with health care use. In addition, despite advances in evidence-based medicine and its contribution toward mitigating variations in health care practice among settings, the disease-specific treatment options that are available and that constitute best practice may vary among (and within) countries. These differences ultimately influence the generalizability and interpretation of the individual estimates.

\section{Differences in Measurement of CHE}

The studies consulted measured CHE using different definitions, thresholds, and categories of expenditure included as out-of-pocket costs, different data sources, and different recall periods, which potentially introduced measurement error. However, the findings from a sensitivity analysis indicated that our results were robust despite the combining of varied estimates.

\section{Differences in Quality and Breadth of Evidence}

Given the lack of comprehensive evidence on the level of $\mathrm{CHE}$ in different populations, estimates for one setting sometimes were based on data extrapolated from studies conducted in other settings. In cases where data on the prevalence of CHE for any particular country income category were missing, we applied a conservative strategy of using the estimate from the next-highest income category. In addition, the results describe the relative burden of disease-related $\mathrm{CHE}$ between conditions and country-income categories but not the potential distributional burden within the populations in each category.

Much of the evidence on the disease-related burden of CHE is from cross-sectional studies that lack a control group and cannot capture repeat expenditures, so they are limited in their ability to attribute $\mathrm{CHE}$ directly to the disease or injuries. In addition, the smaller, clinicbased studies may not be fully representative of the population with disease in each country. Despite their limitations, these studies are the sole source of evidence and provide a starting point from which to investigate differences in the burden of $\mathrm{CHE}$ among different categories of chronic conditions.

The evidence also tends to come from smaller studies of cohorts recruited from hospitals or health care facilities, which can lead to higher estimates of health care expenditure than those based on community or household samples (Lavado, Brooks, and Hanlon 2013; Raban, Dandona, and Dandona 2013). Hospital expenses may explain some of this difference, because the samples in hospitals are a biased (nonrandom) sample of the population. Moreover, household samples were asked to report costs associated with previous hospitalizations, which suggests that recall bias may be stronger in 
the community-based studies than in the clinic- or hospital-based studies.

\section{POLICY DIRECTIONS FOR IMPROVING FINANCIAL PROTECTION}

As the epidemiological transition progresses over the next few decades, the double burden of infectious diseases and NCDs will continue to challenge health care systems in LMICs, which will be confronted with caring for older and more costly populations. Catastrophic and impoverishing health expenditure will increase globally unless action is taken to offer deeper packages of financial protection that include the treatment of chronic disease and injury. In formulating measures to address this issue, policy makers focus on universal health coverage, which aims to provide population-wide protection through various social health protection mechanisms. However, given severe resource constraints, such programs are often able to provide only limited protection of certain diseases and treatments; achieving comprehensive financial protection will inevitably be a longterm goal. The design of the package of entitlements and covered services should take into account both the populations most at risk and the diseases and conditions that drive catastrophic and impoverishing health expenditure. Country examples exist of how to implement this through progressive universalism (Gwatkin and Ergo 2011; Jamison and others 2013); one example, about which much has been written, is the catastrophic expenditure fund of Mexico's Seguro Popular (Knaul, ArreolaOrnelas, and Méndez-Carniado 2016).

In this study, we identify significant variation in the household economic burden by condition. The high burden observed for many chronic conditions such as renal diseases indicates potential areas where targeted programs could be developed to address the populations currently experiencing the greatest financial burden. These results suggest that universal health coverage should be developed as part of a multipronged strategy that addresses not only system-level drivers of the household economic burden but also disease-specific drivers. For individual diseases, basic packages should include specific interventions that are shown to be effective-for example, low-cost dialysis (Liyanage and others 2015) and polypill treatments for CVD (Webster and Rodgers 2016) as well as disease management and prevention strategies.

The research on disease-related CHE tends to be clustered in areas that do not necessarily reflect the diseases that have the greatest burden and largest household economic effect. Under-researched areas such as mental illness should not be overlooked when developing strategies to improve financial risk protection.

This study has important implications for the design of benefit packages. The conventional approach has been to place cost-effectiveness or best buys as the overriding consideration in designing benefit packages (Chisholm and others 2012; Evans and Etienne 2010; WHO and World Economic Forum 2011). The rationale for this approach is strong: given severe resource constraints, priority needs to be given to funding programs that deliver the greatest health outcomes for the dollar. However, although this approach promotes the objective of health maximization, it does not directly address the problem that such benefit packages are designed to address-that is, financial protection. This study provides evidence to guide policy makers in the design of benefit packages and entitlements. It demonstrates the need to prioritize the relative financial burden across disease areas and in different settings to ensure coverage of the disease-specific health care and healthrelated services that are most associated with catastrophic and impoverishing health expenditure (Jamison and others 2013).

This research also highlights the need for an ongoing focus on and investment in prevention. The most effective way to reduce disease-related CHE is to prevent such conditions. This prevention is particularly critical in LMICs, where the double burden of infectious diseases and NCDs continues to place a major strain on health care systems. Evidence from the extended costeffectiveness literature has demonstrated the gains to be made in strengthening financial protection through investment in prevention. Public financing of programs such as vaccination for human papillomavirus infection and management of risk factors, such as obesity for diabetes and hypertension for CVD, have been shown to have the potential to curb catastrophic and impoverishing health expenditure significantly, thereby enhancing financial protection across populations (Levin and others 2015; Verguet and others 2015).

Addressing the factors that lead to and perpetuate entrenched poverty will also produce the greatest gains in mitigating the economic burden of chronic ill health experienced by households. Rates of catastrophic and impoverishing health expenditure should decline over time as universal health coverage is implemented alongside other poverty reduction strategies, including efforts to meet the Sustainable Development Goals. These efforts should reduce the burden of disease overall and improve the capacity of households to access and use required health care services. In monitoring progress, including the effect of efforts to reach the Sustainable Development Goals, priority should be given to 
evaluating changes in financial protection among the population as a whole as well as within subgroups most at risk of catastrophic and impoverishing health expenditure.

\section{FUTURE RESEARCH DIRECTIONS}

More prospective longitudinal studies are needed to examine the extent to which households can recover from the burden of catastrophic and impoverishing health expenditure. These types of studies, although few, have helped identify the determinants of recovery from an illness shock as well as factors that potentially enhance resilience to such shocks (Essue and others 2012; Heeley and others 2009; Jan and others 2015; Jan and others 2016; Kimman and others 2015). Prospective studies will also help distinguish between the effect and consequences of one shock versus cumulative expenditure as well as the potential for health interventions to improve household economic circumstances (Essue and others 2014; Kuper and others 2010).

Longitudinal research is also needed to monitor progress in mitigating $\mathrm{CHE}$ and impoverishing health expenditure. Monitoring progress using different crosssections of population data over time cannot account well for the fact that new households may encounter $\mathrm{CHE}$, while others may become nonspenders because they are no longer able to pay for care. Therefore, declines over time do not necessarily mean that health care has become more affordable for all.

Furthermore, the long-term effect on households of impoverishing health expenditure, distressed financing arrangements, changes in workforce participation, and treatment discontinuation are poorly understood. More multidimensional assessments of the household economic burden of chronic ill health are needed using routinely measured indicators along with $\mathrm{CHE}$ and impoverishing health expenditure (Moreno-Serra, Millet, and Smith 2011; Ruger 2012). Such studies would support the design of financial protection programs and improve the targeting of interventions, because these indicators provide greater insights into the effect of illness and health care expenditure on the household economy.

More research is needed to understand the link back to health. Although the effect of the social determinants of health is well understood (Friel and Marmot 2011), longer-term cohort studies are needed to assess how these economic consequences perpetuate the cycle of chronic ill health and social disadvantage (van Doorslaer and others 2006). Evidence on the link between the economic burden of disease, health outcomes, and social disadvantage would strengthen the economic case for improving access to affordable care.

\section{CONCLUSIONS}

In this chapter, we estimate the economic burden associated with seven categories of chronic conditions as well as injuries. We find that most CHE is due to renal, cardiovascular, and chronic infectious diseases and that the global burden of $\mathrm{CHE}$ is much higher than previously estimated.

Meeting the global commitment to enhance financial protection of populations, including the World Bank's goal of eliminating impoverishing health expenditure by 2030 , requires a concerted effort to address the main drivers of $\mathrm{CHE}$ in all settings. In designing financial protection programs, policy makers need to give priority to covering populations and conditions associated with the greatest economic burden. Furthermore, needed health care services still remain out of reach for millions with disease who live in poverty. Strategies to enhance financial protection need to be implemented alongside broader poverty alleviation efforts, which collectively will generate the greatest gains in mitigating the household-level economic burden of chronic ill health globally.

\section{ANNEXES}

The annexes to this chapter are as follows. They are available at http://www.dcp-3.org/DCP.

- Annex 6A. Description of Data Sources and Search Strategy.

- Annex 6B. Search Strategy for Prospectively Designed Studies of Household Economic Effect of Chronic Disease.

\section{NOTE}

World Bank Income Classifications as of July 2014 are as follows, based on estimates of gross national income (GNI) per capita for 2013:

- Low-income countries (LICs) $=$ US $\$ 1,045$ or less

- Middle-income countries (MICs) are subdivided:

(a) lower-middle-income $=$ US $\$ 1,046$ to US $\$ 4,125$

(b) upper-middle-income (UMICs) $=$ US $\$ 4,126$ to US $\$ 12,745$

- High-income countries (HICs) = US\$12,746 or more.

\section{ACKNOWLEDGMENTS}

The authors are grateful to Ke Xu for the input received on the structure and scope of this chapter early on as well as to the teams in Mongolia, the Philippines, and Vietnam for their contribution to the case studies presented in box 6.2. Financial protection information 
from Mongolia was taken from a WHO-commissioned report on catastrophic health payments and benefit incidence of government expenditure in Mongolia conducted by Tsolmongerel Tsilaajav, Oyungerel Nanzad, and Enkhbaatar Ichinnorov, under the coordination of Erdenechimeg Enkhee of the Office of the WHO Representative in Mongolia. We also acknowledge the contribution of Melanie Bisnauth, who provided research assistance to support the analysis in this chapter.

\section{REFERENCES}

Afshar, S., P. J. Roderick, P. Kowal, B. D. Dimitrov, and A. G. Hill. 2015. "Multimorbidity and the Inequalities of Global Ageing: A Cross-Sectional Study of 28 Countries Using the World Health Surveys." BMC Public Health 5 (776): 1-10. doi:10.1186/s12889-015-2008-7.

Aggarwal, A., and R. Sullivan. 2014. "Achieving Value in Cancer Care: The Case of Low- and Middle-Income Countries." American Journal of Managed Care 20 (12): 292-94.

Alam, K., and A. Mahal. 2014. "The Economic Burden of Angina on Households in South Asia." BMC Public Health 14 (February): 179.

Alvarez-Hernandez, E., I. Pelaez-Ballestas, A. Boonen, J. Vázquez-Mellado, A. Hernández-Garduño, and others. 2012. "Catastrophic Health Expenses and Impoverishment of Households of Patients with Rheumatoid Arthritis." Reumatología Clínica 8 (4): 168-73.

Arora, R. S., T. Eden, and B. Pizer. 2007. "The Problem of Treatment Abandonment in Children from Developing Countries with Cancer." Pediatric Blood and Cancer 49 (7): 941-46.

Banthin, J. S., and D. M. Bernard. 2006. "Changes in Financial Burdens for Health Care: National Estimates for the Population Younger than 65 Years, 1996 to 2003." Journal of the American Medical Association 296 (22): 2712-19.

Barennes, H., A. Frichittavong, M. Gripenberg, and P. Koffi. 2015. "Evidence of High Out-of-Pocket Spending for HIV Care Leading to Catastrophic Expenditure for Affected Patients in Lao People's Democratic Republic.” PLoS One 10 (9): e0136664.

Beaglehole, R., R. Bonita, R. Horton, C. Adams, G. Alleyne, and others. 2011. "Priority Actions for the Non-Communicable Disease Crisis." The Lancet 377 (9775): 1438-47.

Beauliere, A., S. Toure, P. K. Alexandre, K. Koné, A. Pouhé, and others. 2010. "The Financial Burden of Morbidity in HIVInfected Adults on Antiretroviral Therapy in Côte d'Ivoire." PLoS One 5 (6): e11213.

Bhojani, U., T. S. Beerenahalli, R. Devadasan, C. M. Munegowda, N. Devadasan, and others. 2013. "No Longer Diseases of the Wealthy: Prevalence and Health-Seeking for Self-Reported Chronic Conditions among Urban Poor in Southern India." BMC Health Services Research 13 (August): 1-10.

Bhojani, U., B. Thriveni, R. Devadasan, C. M. Munegowda, N. Devadasan, and others. 2012. "Out-of-Pocket Healthcare
Payments on Chronic Conditions Impoverish Urban Poor in Bangalore, India." BMC Public Health 12 (990): 1-13.

Boyer, S., M. Abu-Zaineh, J. Blanche, S. Loubiere, R. C. Bonono, and others. 2011. "Does HIV Services Decentralization Protect Against the Risk of Catastrophic Health Expenditures? Some Lessons from Cameroon." Health Services Research 46 (6): 2029-56.

Burke, R. M., E. R. Smith, R. M. Dahl, P. A. Rebolledo, C. Calderón Mdel, and others. 2014. "The Economic Burden of Pediatric Gastroenteritis to Bolivian Families: A Cross-Sectional Study of Correlates of Catastrophic Cost and Overall Cost Burden." BMC Public Health 14 (June): 642.

Cameron, A., M. Ewen, D. Ross-Degnan, D. Ball, and R. Laing. 2009. "Medicine Prices, Availability, and Affordability in 36 Developing and Middle-Income Countries: A Secondary Analysis." The Lancet 373 (9659): 240-49.

Castillo-Riquelme, M., D. McIntyre, and K. Barnes. 2008. "Household Burden of Malaria in South Africa and Mozambique: Is there a Catastrophic Impact?" Tropical Medicine and International Health 13 (1): 108-22.

Che, Y. H., V. Chongsuvivatwong, L. Li, H. Sriplung, Y. Y. Wang, and others. 2016. "Financial Burden on the Families of Patients with Hepatitis B Virus-Related Liver Diseases and the Role of Public Health Insurance in Yunnan Province of China." Public Health 130 (January): 13-20.

Chen, S., H. Zhang, Y. Pan, Q. Long, L. Xiang, and others. 2015. "Are Free Anti-Tuberculosis Drugs Enough? An Empirical Study from Three Cities in China." Infectious Diseases of Poverty 4 (October): 47.

Chisholm, D., R. Baltussen, D. B. Evans, G. Ginsberg, J. A. Lauer, and others. 2012. "What Are the Priorities for Prevention and Control of Non-Communicable Diseases and Injuries in Sub-Saharan Africa and South East Asia?" British Medical Journal 344 (March): e586.

Choi, J.-W., K. H. Cho, Y. Choi, K. T. Han, J. A. Kwon, and others. 2014. "Changes in Economic Status of Households Associated with Catastrophic Health Expenditures for Cancer in South Korea." Asian Pacific Journal of Cancer Prevention 15 (6): 2713-17.

Choi, J.-W., J.-W. Choi, J.-H. Kim, K.-B. Yoo, and E.-C. Park. 2015. "Association between Chronic Disease and Catastrophic Health Expenditure in Korea." BMC Health Services Research 15 (1): 464-78.

Cleary, S. M., S. Birch, M. Moshabela, and H. Schneider. 2012. "Unequal Access to ART: Exploratory Results from Rural and Urban Case Studies of ART Use." Sexually Transmitted Infections 88 (2): 141-46.

Daivadanam, M., K. R. Thankappan, P. S. Sarma, and S. Harikrishnan. 2012. "Catastrophic Health Expenditure and Coping Strategies Associated with Acute Coronary Syndrome in Kerala, India." Indian Journal of Medical Research 136 (4): 585-92.

Dalaba, M. A., P. Akweongo, R. A. Aborigo, H. P. Saronga, J. Williams, and others. 2015. "Cost to Households in Treating Maternal Complications in Northern Ghana: A Cross-Sectional Study." BMC Health Services Research 15 (January): 34. 
Dalal, K., Z. Lin, M. Gifford, and L. Svanström. 2013. "Economics of Global Burden of Road Traffic Injuries and Their Relationship with Health System Variables." International Journal of Preventive Medicine 4 (12): 1442-50.

Davidoff, A. J., M. Erten, T. Shaffer, J. S. Shoemaker, I. H. Zuckerman, and others. 2013. "Out-of-Pocket Health Care Expenditure Burden for Medicare Beneficiaries with Cancer." Cancer 119 (6): 1257-65.

Engelgau, M. M., A. Karan, and A. Mahal. 2012. "The Economic Impact of Non-Communicable Diseases on Households in India." Globalization and Health 8 (1): 9.

Essue, B. M., M. Hackett, Q. Li, N. Glozier, R. Lindley, and others. 2012. "How Are Household Economic Circumstances Affected after a Stroke? The Psychosocial Outcomes In StrokE (POISE) Study." International Journal of Stroke 7 (September): 36.

Essue, B. M., P. Kelly, M. Roberts, S. Leeder, and S. Jan. 2011. "We Can't Afford My Chronic Illness! The Out-of-Pocket Burden Associated with Managing Chronic Obstructive Pulmonary Disease in Western Sydney, Australia." Journal of Health Services Research and Policy 16 (4): 226-31.

Essue, B. M., M. Kimman, N. Svenstrup, K. L. Kjoege, T. L. Laba, and others. 2015. "The Effectiveness of Interventions to Reduce the Household Economic Burden of Illness and Injury: A Systematic Review." Bulletin of the World Health Organization 93 (2): 102-12B.

Essue, B. M., Q. Li, M. L. Hackett, L. Keay, B. Lezzi, and others. 2014. "A Multicenter Prospective Cohort Study of Quality of Life and Economic Outcomes after Cataract Surgery in Vietnam: The VISIONARY Study." Ophthalmology 121 (11): 2138-46.

Essue, B. M., G. Wong, J. Chapman, Q. Li, and S. Jan. 2013. "How Are Patients Managing with the Costs of Care for Chronic Kidney Disease in Australia? A Cross-Sectional Study.” BMC Nephrology 14 (January): 5.

Evans, D. B., and C. Etienne. 2010. "Health Systems Financing and the Path to Universal Coverage." Bulletin of the World Health Organization 88 (6): 402.

Frenk, J., J. L. Bobadilla, J. Sepuúlveda, and M. Cervantes. 1989. "Health Transition in Middle-Income Countries: New Challenges for Health Care." Health Policy and Planning 4 (1): 29-39.

Friel, S., and M. G. Marmot. 2011. "Action on the Social Determinants of Health and Health Inequities Goes Global." Annual Review of Public Health 32 (April): 225-36.

Gelders, S., M. Ewen, N. Noguchi, and R. Laing. 2006. Price, Availability, and Affordability: An International Comparison of Chronic Disease Medicines. Cairo: World Health Organization Regional Office for the Eastern Mediterranean and Health Action International.

Gertler, P., and J. Gruber. 2002. "Insuring Consumption against Illness.” American Economic Review 92 (March): 51-70.

Global Burden of Disease Study 2013 Collaborators. 2015. "Global, Regional, and National Incidence, Prevalence, and Years Lived with Disability for 301 Acute and Chronic Diseases and Injuries in 188 Countries, 1990-2013: A Systematic Analysis for the Global Burden of Disease Study 2013." The Lancet 386 (9995): 743-800.
Goeppel, C., P. Frenz, L. Grabenhenrich, T. Keil, and P. Tinnemann. 2016. "Assessment of Universal Health Coverage for Adults Aged 50 Years or Older with Chronic Illness in Six Middle-Income Countries." Bulletin of the World Health Organization 94 (4): 276-85C.

Gwatkin, D. R., and A. Ergo. 2011. "Universal Health Coverage: Friend or Foe of Health Equity?” The Lancet 377 (9784): 2160-61.

Hamid, S. A., S. M.Ahsan, and A. Begum. 2014. "Disease-Specific Impoverishment Impact of Out-of-Pocket Payments for Health Care: Evidence from Rural Bangladesh.” Applied Health Economics and Health Policy 12 (4): 421-33.

Heeley, E., C. A. Anderson, Y. Huang, S. Jan, Y. Li, and others. 2009. "Role of Health Insurance in Averting Economic Hardship in Families after Acute Stroke in China." Stroke 40 (6): 2149-56.

Htet, S., K. Alam, and A. Mahal. 2015. "Economic Burden of Chronic Conditions among Households in Myanmar: The Case of Angina and Asthma." Health Policy and Planning 30 (9): 1173-83.

Huffman, M. D., K. D. Rao, A. Pichon-Riviere, D. Zhao, S. Harikrishnan, and others. 2011. "A Cross-Sectional Study of the Microeconomic Impact of Cardiovascular Disease Hospitalization in Four Low- and Middle-Income Countries.” PLoS One 6 (6): e20821.

Human Rights Watch. 2006. "A High Price to Pay: Detention of Poor Patients in Burundian Hospitals." Human Rights Watch, September 7.

Ilunga-Ilunga, F., A. Leveque, S. Laokri, and M. Dramaix. 2015. "Incidence of Catastrophic Health Expenditures for Households: An Example of Medical Attention for the Treatment of Severe Childhood Malaria in Kinshasa Reference Hospitals, Democratic Republic of Congo." Journal of Infection and Public Health 8 (2): 136-44.

Israels, T., C. Chirambo, H. Caron, J. de Kraker, E. Molyneux, and others. 2008. “The Guardians' Perspective on Paediatric Cancer Treatment in Malawi and Factors Affecting Adherence." Pediatric Blood and Cancer 51 (5): 639-42.

Jamison, D. T., L. H. Summers, G. Alleyne, K. J. Arrow, S. Berkley, and others. 2013. "Global Health 2035: A World Converging within a Generation.” The Lancet 382 (9908): 1898-955.

Jan, S., M. Kimman, S. A. E. Peters, and M. Woodward. 2015. "Financial Catastrophe, Treatment Discontinuation, and Death Associated with Surgically Operable Cancer in South-East Asia: Results from the ACTION Study." Surgery 157 (6): 971-82.

Jan, S., S. W. L. Lee, J. P. S. Sawhney, T. K. Ong, C. T. Chin, and others. 2016. "Catastrophic Health Expenditure on Acute Coronary Events in Asia: A Prospective Study." Bulletin of the World Health Organization 94 (3): 193-200.

Kankeu, H. T., P. Saksena, K. Xu, and D. B. Evans. 2013. “The Financial Burden from Non-Communicable Diseases in Low- and Middle-Income Countries: A Literature Review." Health Research Policy and Systems 11 (August): 1-12.

Kavosi, Z., H. Delavari, A. Keshtkaran, and F. Setoudehzadeh. 2014. "Catastrophic Health Expenditures and Coping Strategies in Households with Cancer Patients in 
Shiraz Namazi Hospital.” Middle East Journal of Cancer 5 (1): 13-22.

Khatib, R., M. McKee, H. Shannon, C. Chow, S. Rangarajan, and others. 2016. "Availability and Affordability of Cardiovascular Disease Medicines and their Effect on Use in High-Income, Middle-Income, and Low-Income Countries: An Analysis of the PURE Study Data." The Lancet 387 (10013): 61-69.

Kim, J. Y. 2014. “Speech by World Bank Group President Jim Yong Kim on Universal Health Coverage in Emerging Economies." Conference on Universal Health Coverage in Emerging Economies, Center for Strategic and International Studies, Washington, DC, January 14.

Kimman, M., S. Jan, C. H. Yip, H. Thabrany, S. A. Peters, and others. 2015. "Catastrophic Health Expenditure and 12-Month Mortality Associated with Cancer in Southeast Asia: Results from a Longitudinal Study in Eight Countries." BMC Medicine 13 (August): 190.

Knaul, F. M., H. Arreola-Ornelas, and O. Méndez-Carniado. 2016. "Protección financiera en salud: Actualizaciones para México a 2014.” Salud Pública de México 58 (3): 341-50.

Knaul, F. M., H. Arreola-Ornelas, O. Méndez-Carniado, C. Bryson-Cahn, J. Barofsky, and others. 2006. "Evidence Is Good for Your Health System: Policy Reform to Remedy Catastrophic and Impoverishing Health Spending in Mexico." The Lancet 368 (9549): 1828-41.

Knaul, F. M., R. Wong, and H. Arreola-Ornelas, eds. 2012. Household Spending and Impoverishment. Vol. 1, Financing Health in Latin America. Cambridge, MA: Harvard Global Equity Initiative, Mexican Health Foundation, and International Development Research Centre.

Kruk, M. E., E. Goldmann, and S. Galea. 2009. "Borrowing and Selling to Pay for Health Care in Low- and Middle-Income Countries." Health Affairs 28 (4): 1056-66.

Kumar, G. A., T. R. Dilip, L. Dandona, and R. Dandona. 2012. "Burden of Out-of-Pocket Expenditure for Road Traffic Injuries in Urban India." BMC Health Services Research 12 (August): 285.

Kuper, H., S. Polack, W. Mathenge, C. Eusebio, Z. Wadud, and others. 2010. "Does Cataract Surgery Alleviate Poverty? Evidence from a Multi-Centre Intervention Study Conducted in Kenya, the Philippines, and Bangladesh." PLoS One 5 (11): e15431.

Lange, S., C. Diehm, H. Darius, R. Haberl, J. R. Allenberg, and others. 2004. "High Prevalence of Peripheral Arterial Disease and Low Treatment Rates in Elderly Primary Care Patients with Diabetes." Experimental and Clinical Endocrinology and Diabetes 112 (10): 566-73.

Laokri, S., M. Dramaix-Wilmet, F. Kassa, S. Anagonou, and B. Dujardin. 2014. "Assessing the Economic Burden of Illness for Tuberculosis Patients in Benin: Determinants and Consequences of Catastrophic Health Expenditures and Inequities." Tropical Medicine and International Health 19 (10): 1249-58.

Lavado, R. F., B. P. Brooks, and M. Hanlon. 2013. "Estimating Health Expenditure Shares from Household Surveys." Bulletin of the World Health Organization 91 (7): 519-24.
Levin, C. E., M. Sharma, Z. Olson, S. Verguet, J. F. Shi, and others. 2015. "An Extended Cost-Effectiveness Analysis of Publicly Financed HPV Vaccination to Prevent Cervical Cancer in China." Vaccine 33 (24): 2830-41.

Li, W., H. Gu, K. K. Teo, J. Bo, Y. Wang, and others. 2016. "Hypertension Prevalence, Awareness, Treatment, and Control in 115 Rural and Urban Communities Involving 47,000 People from China." Journal of Hypertension 34 (1): 39-46.

Li, Y., Q. Wu, L. Xu, D. Legge, Y. Hao, and others. 2012. "Factors Affecting Catastrophic Health Expenditure and Impoverishment from Medical Expenses in China: Policy Implications of Universal Health Insurance." Bulletin of the World Health Organization 90 (9): 664-71.

Liyanage, T., T. Ninomiya, V. Jha, B. Neal, H. M. Patrice, and others. 2015. "Worldwide Access to Treatment for EndStage Kidney Disease: A Systematic Review.” The Lancet 385 (9981): 1975-82.

Loganathan, T., W. S. Lee, K. F. Lee, M. Jit, and C. W. Ng. 2015. "Household Catastrophic Healthcare Expenditure and Impoverishment Due to Rotavirus Gastroenteritis Requiring Hospitalization in Malaysia." PLoS One 10 (5): e0125878.

Mahal, A., A. Karan, V. Y. Fan, and M. Engelgau. 2013. "The Economic Burden of Cancers on Indian Households." PLoS One 8 (8): e71853.

McIntyre, D., M. Thiede, G. Dahlgren, and M. Whitehead. 2006. "What Are the Economic Consequences for Households of Illness and of Paying for Health Care in Low- and MiddleIncome Country Contexts?" Social Science and Medicine 62 (4): 858-65.

Minh, H. V., and N. T. P. Phuong. 2016. "Burden of Household Out-of-Pocket Health Expenditures in Vietnam." Working Paper, Hanoi School of Public Health, Hanoi.

Moreno-Serra, R., C. Millett, and P. C. Smith. 2011. "Towards Improved Measurement of Financial Protection in Health.” PLoS Medicine 8 (9): e1001087.

Moshabela, M., H. Schneider, S. P. Silal, and S. M. Cleary. 2012. "Factors Associated with Patterns of Plural Healthcare Utilization among Patients Taking Antiretroviral Therapy in Rural and Urban South Africa: A Cross-Sectional Study." BMC Health Services Research 12 (July): 182.

Murphy, A., A. Mahal, E. Richardson, and A. E. Moran. 2013. "The Economic Burden of Chronic Disease Care Faced by Households in Ukraine: A Cross-Sectional Matching Study of Angina Patients." International Journal for Equity in Health 12 (May): 38.

Nguyen, H., R. Ivers, S. Jan, A. Martiniuk, and C. Pham. 2013. "Catastrophic Household Costs Due to Injury in Vietnam." Injury 44 (5): 684-90.

O'Donnell, O., E. van Doorslaer, A. Wagstaff, and M. Lindelow, eds. 2007. Analyzing Health Equity Using Household Survey Data: A Guide to Techniques and Their Implementation. Washington, DC: World Bank Group.

Okoli, C. I., and S. M. Cleary. 2011. "Socioeconomic Status and Barriers to the Use of Free Antiretroviral Treatment for HIV/AIDS in Enugu State, South-Eastern Nigeria." African Journal of AIDS Research 10 (2): 149-55. 
Patel, V., D. Chisholm, B. R. Kirkwood, and D. Mabey. 2007. "Prioritizing Health Problems in Women in Developing Countries: Comparing the Financial Burden of Reproductive Tract Infections, Anaemia, and Depressive Disorders in a Community Survey in India." Tropical Medicine and International Health 12 (1): 130-39.

Peters, D. H., A. Garg, G. Bloom, D. G. Walker, W. R. Brieger, and others. 2008. "Poverty and Access to Health Care in Developing Countries." Annals of the New York Academy of Sciences 1136 (October): 161-71.

Prakongsai, P., N. Palmer, P. Uay-Trakul, V. Tangcharoensathien, and A. Mills. 2009. "The Implications of Benefit Package Design: The Impact on Poor Thai Households of Excluding Renal Replacement Therapy." Journal of International Development 21 (2): 291-308.

Pramesh, C. S., R. A. Badwe, B. B. Borthakur, M. Chandra, E. Hemanth Raj, and others. 2014. "Delivery of Affordable and Equitable Cancer Care in India." The Lancet Oncology 15 (6): e223-33.

Raban, M. Z., R. Dandona, and L. Dandona. 2013. "Variations in Catastrophic Health Expenditure Estimates from Household Surveys in India." Bulletin of the World Health Organization 91 (10): 726-35.

Ramachandran, R., and V. Jha. 2013. "Kidney Transplantation Is Associated with Catastrophic Out-of-Pocket Expenditure in India." PLoS One 8 (7): e67812.

Rocha-Garcia, A., P. Hernandez-Pena, S. Ruiz-Velazco, L. AvilaBurgos, T. Marin-Palomares, and others. 2003. "Out-ofPocket Expenditures during Hospitalization of Young Leukemia Patients with State Medical Insurance in Two Mexican Hospitals [Spanish]." Salud Pública de México 45 (4): 285-92.

Ruger, J. P. 2012. "An Alternative Framework for Analyzing Financial Protection in Health." PLoS Medicine 9 (8): e1001294.

Russell, S. 2004. "The Economic Burden of Illness for Households in Developing Countries: A Review of Studies Focusing on Malaria, Tuberculosis, and Human Immunodeficiency Virus/Acquired Immunodeficiency Syndrome." American Journal of Tropical Medicine and Hygiene 71 (Suppl 2): 147-55.

Saito, E., S. Gilmour, M. M. Rahman, G. S. Gautam, P. K. Shrestha, and others. 2014. "Catastrophic Household Expenditure on Health in Nepal: A Cross-Sectional Survey." Bulletin of the World Health Organization 92 (10): 760-67.

Sauerborn, R., A. Adams, and M. Hien. 1996. "Household Strategies to Cope with the Economic Costs of Illness." Social Science and Medicine 43 (3): 291-301.

Schoen, C., R. Osborn, D. Squires, M. M. Doty, R. Pierson, and others. 2010. "How Health Insurance Design Affects Access to Care and Costs, by Income, in Eleven Countries." Health Affairs 29 (12): 2323-34.

Schoenberg, N. E., H. Kim, W. Edwards, and S. T. Fleming. 2007. "Burden of Common Multiple-Morbidity Constellations on Out-of-Pocket Medical Expenditures among Older Adults." Gerontologist 47 (4): 423-37.
Shrime, M. G., A. J. Dare, B. C. Alkire, K. O'Neill, and J. G. Meara. 2015. "Catastrophic Expenditure to Pay for Surgery Worldwide: A Modelling Study." The Lancet Global Health 3 (Suppl 2): S38-44.

Skroumpelos, A., E. Pavi, S. Pasaloglou, and J. Kyriopoulos. 2014. "Catastrophic Health Expenditures and Chronic Condition Patients in Greece." Value in Health 17 (7): A501-02.

Smith-Spangler, C. M., J. Bhattacharya, and J. D. GoldhaberFiebert. 2012. "Diabetes, Its Treatment, and Catastrophic Medical Spending in 35 Developing Countries." Diabetes Care 35 (2): 319-26.

Sun, J., T. Liabsuetrakul, Y. Fan, and E. McNeil. 2015. "Protecting Patients with Cardiovascular Diseases from Catastrophic Health Expenditure and Impoverishment by Health Finance Reform." Tropical Medicine and International Health 20 (12): 1846-54.

Sustainable Development Solutions Network. 2014. "Health in the Framework of Sustainable Development: Technical Report for the Post-2015 Development Agenda." Thematic Group on Health for All, Sustainable Development Solutions Network, New York.

Teerawattananon, Y., A. Luz, S. Pilasant, S. Tangsathitkulchai, S. Chootipongchaivat, and others. 2016. "How to Meet the Demand for Good Quality Renal Dialysis as Part of Universal Health Coverage in Resource-Limited Settings?" Health Research Policy and Systems 14 (March): 21.

Thuan, N. T., C. Lofgren, N. T. Chuc, U. Janlert, and L. Lindholm. 2006. "Household Out-of-Pocket Payments for Illness: Evidence from Vietnam.” BMC Public Health 6 (November): 283.

Tran, B. X., A. T. Duong, L. T. Nguyen, J. Hwang, B. T. Nguyen, and others. 2013. "Financial Burden of Health Care for HIV/AIDS Patients in Vietnam." Tropical Medicine and International Health 18 (2): 212-18.

Tsilaajav, T., O. Nanzad, and E. Ichinnorov. 2015. "Analysis of Catastrophic Health Payments and Benefit Incidence of Government Spending for Health in Mongolia.” Paper commissioned for the World Health Organization, Western Pacific Regional Office, Manila.

Ulep, G. T., and N. A. O. dela Cruz. 2013. "Analysis of Out-ofPocket Expenditures in the Philippines." Philippine Journal of Development 40 (1-2d).

UN (United Nations) General Assembly. 2015. "Seventieth Session. Resolution A/RES/70/1: Transforming Our World: The 2030 Agenda for Sustainable Development." UN, New York, October 21.

van Doorslaer, E., O. O'Donnell, R. P. Rannan-Eliya, A. Somanathan, S. R. Adhikari, and others. 2006. "Effect of Payments for Health Care on Poverty Estimates in 11 Countries in Asia: An Analysis of Household Survey Data." The Lancet 368 (9544): 1357-64.

Van Minh, H., and B. X. Tran. 2012. "Assessing the Household Financial Burden Associated with the Chronic NonCommunicable Diseases in a Rural District of Vietnam." Global Health Action 5 (December): 1-7. 
Verguet, S., Z. D. Olson, J. B. Babigumira, D. Desalegn, K. A. Johansson, and others. 2015. "Health Gains and Financial Risk Protection Afforded by Public Financing of Selected Interventions in Ethiopia: An Extended Cost-Effectiveness Analysis." The Lancet Global Health 3 (5): e288-96.

Wagstaff, A., and E. van Doorslaer. 2003. "Catastrophe and Impoverishment in Paying for Health Care: With Applications to Vietnam 1993-1998." Health Economics 12 (11): 921-34.

Wang, J., H. W. Zhou, Y. X. Lei, and X. W. Wang. 2012. "Financial Protection under the New Rural Cooperative Medical Schemes in China." Medical Care 50 (8): 700-04.

Wang, Q., H. Liu, Z. X. Lu, Q. Luo, and J. A. Liu. 2014. "Role of the New Rural Cooperative Medical System in Alleviating Catastrophic Medical Payments for Hypertension, Stroke, and Coronary Heart Disease in Poor Rural Areas of China." BMC Public Health 14 (1): 907.

Webster, R., and A. Rodgers. 2016. "Polypill Treatments for Cardiovascular Diseases.” Expert Opinion on Drug Delivery 13 (1): 1-6.

White, S. L., S. J. Chadban, S. Jan, J. R. Chapman, and A. Cass. 2008. "How Can We Achieve Global Equity in Provision of Renal Replacement Therapy?" Bulletin of the World Health Organization 86 (3): 229-37.

WHO (World Health Organization). 2000. World Health Report 2000: Health Systems: Improving Performance. Geneva: WHO.

. 2005. "World Health Assembly: Sustainable Health Financing, Universal Coverage, and Social Health Insurance." WHA58.33, WHO, Geneva.

- 2010. The World Health Report: Health Systems Financing: The Path to Universal Coverage. Geneva: WHO.

_. 2014. "Global Health Estimates." WHO, Geneva.

. 2015. "Health and Human Rights." Fact Sheet 323, WHO, Geneva.
- 2016. Global Health Expenditure Database. WHO, Geneva (accessed August 29, 2016), http://apps.who.int /nha/database.

WHO (World Health Organization) and World Bank. 2014. "Monitoring Progress towards Universal Health Coverage at Country and Global Levels: Framework, Measures, and Targets." WHO, Geneva; World Bank, Washington, DC.

WHO (World Health Organization) and World Economic Forum. 2011. From Burden to "Best Buys": Reducing the Economic Impact of Non-Communicable Diseases in Lowand Middle-Income Countries. Geneva: WHO.

Wingfield, T., D. Boccia, M. Tovar, A. Gavino, K. Zevallos, and others. 2014. "Defining Catastrophic Costs and Comparing Their Importance for Adverse Tuberculosis Outcome with Multi-Drug Resistance: A Prospective Cohort Study, Peru.” PLoS Medicine 11 (7): e1001675.

$\mathrm{Xu}$, K. 2005. "Distribution of Health Payments and Catastrophic Expenditures: Methodology." Discussion Paper 2-2005, WHO, Geneva.

$\mathrm{Xu}$, K., D. B. Evans, G. Carrin, A. M. Aguilar-Rivera, P. Musgrove, and others. 2007. "Protecting Households from Catastrophic Health Spending." Health Affairs 26 (4): 972-83.

Xu, K., D. B. Evans, K. Kawabata, R. Zeramdini, J. Klavus, and others. 2003. "Household Catastrophic Health Expenditure: A Multicountry Analysis." The Lancet 362 (9378): 111-17.

Zhang, J., V. Chongsuvivatwong, and A. Geater. 2006. "Clinical Severity and Financial Burden among Road Traffic Injury Patients in Kunming, China." Southeast Asian Journal of Tropical Medicine and Public Health 37 (5): 1034-39.

Zhao, D., W. Wang, J. Liu, M. Wang, J. Sun, and others. 2012. "The Impact of Cardiovascular Disease on Household Economic Well-Being in Chinese Population." Circulation 125 (19): e677-78. 